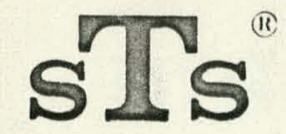

Ann Arbor, Michigan
S T S I N C O R P O R A T E D

Scientific Translation Service

formerly Technical Library Research Service

I

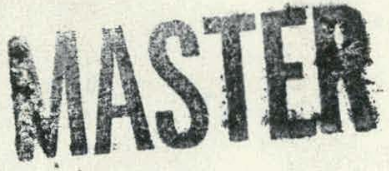

\title{
Oinll.to 1824 \\ THEORETICAL AND EXPERIMENTAL STUDY OF STRUCTURES \\ SUBJECTED TO EARTHQUAKES
}

By A. Soubirou

Annales des Ponts et Chaussées, If: $77-158$ (1967)

\section{LEGAL NOTICE}

This report was prepared as an account of Government sponsored

A. Makes anymission, nor any person acting on behalf of the work. Neither the United racy, completeness warranty or representation, expressed or implied Commission:

racy, completeness, or usefulness of the informationsed or implied, with respect to the accuprivately ownedion, apparatus, method, or process disclained in this report, or that the use

B. Assumes any liabilities with respet to the rist may not infringe use of any information, apparatus, method, or process disclosed in this report.
As used in the above, "person from the ployee or contractor of the "person acting on behalf of the Commission"

such employee or contractor of the Con, or employee of such contractor includes any emdisseminates, or provide oxtent that with the Commission, or

Translated from the French For Oak Ridge National Laboratory Purchase Order No. 34B-60150-V Letter Release No. U-77

sTs Order No. 6123 


\section{DISCLAIMER}

This report was prepared as an account of work sponsored by an agency of the United States Government. Neither the United States Government nor any agency Thereof, nor any of their employees, makes any warranty, express or implied, or assumes any legal liability or responsibility for the accuracy, completeness, or usefulness of any information, apparatus, product, or process disclosed, or represents that its use would not infringe privately owned rights. Reference herein to any specific commercial product, process, or service by trade name, trademark, manufacturer, or otherwise does not necessarily constitute or imply its endorsement, recommendation, or favoring by the United States Government or any agency thereof. The views and opinions of authors expressed herein do not necessarily state or reflect those of the United States Government or any agency thereof. 


\section{DISCLAIMER}

Portions of this document may be illegible in electronic image products. Images are produced from the best available original document. 


\section{Table of Contents}

Part I: GENERAL CONCEPTS ON EARTHQUAKES

Chapter I

Effects of an earthquake

Chapter II Harmonic analysis of seismic stresses

Part II: DYNAMICS OF SYSTEMS WITH $n$ DEGREES OF FREEDOM

Chapter I Free 6scillations of systems with $\mathrm{n}$ degrees of dynamic freedom

Chapter II

Forced vibrations of systems with

$n$ degrees of dynamic freedom due to

a seismic shock

Chapter III Calculation of seismic forces in a lattice structure by the method of modal analysis

Part III: METHODS OF CAICULATION

Chapter I Calculation of seismic spectra

Chapter II

Practical determination of natural frequencies of vibration and of damping

Chapter III Modern methods of calculation of seismic forces: paraseismic criteria 40

PART IV: ELASTIC-PLASTIC BEHAVIOR OF STRUCTURES

Chapter I

Study of the elastic-plastic behavior of structures

Conclusion 


\title{
THEORETICAL AND EXPERIMENTAL STUDY OF STRUCTURES
}

\author{
SUBJECTED TO EARTHQUAKES ${ }^{1}$ \\ By A. Soubirou \\ C1vil Engineer of Bridges and Roads
}

\section{SUMIMARY}

Theoretical and experimental study of the bchaviour of structures subject to earthqualces

The object of the study was the investigation of the behaviour of strustures subject to earthiquakes.

After describing and analysing seismic movements, useful concepts for earthquake-proofing structures are introduced.

Then, the dynamic behaviour of systems with " $\mathrm{n}$ n degrees of freedom was studied in order to evolve the theoretical computation of seismic behaviour, a typical application being reticulated structures.

The next stage was showing the computational procedure for seismic spectra and the natural frequencies of buildings, an attempt being made to define earthquake-proofing criteria for a special type of reinforeed-concretc construction. importance.

The last matter dealt with is elastoplastic behaviour of structures, a study of increasingly growing

\section{PART I}

\section{GENERAL CONCEPTS ON EARTHQUAKES \\ Chapter I--Effects of an Earthquake}

A. Selsmic Waves

On the surface of the earth, an earthquake becomes manffest by unpredictable displacements in space. The trajectory of a point is a spatial curve.

Fig. 1 represents the displacements of a point on the three axes of a coordinate system as a function of time $t$.

The displacements of a point result from waves generated by the earthquake focus (hypocenter).

If we consider an infinite, homogeneous and isotropic elastic medium to which a sharp displacement is applied at a point, this disturbance generates two types of waves: 
Radial compressional or longitudinal waves, analogous to sound waves identified by $P$ which propagate from the focus at a velocity:

$$
\therefore v_{l}=\sqrt{\frac{2(\sigma-1) G}{\sigma-2} \frac{G}{\rho}}=\sqrt{\frac{\sigma(\sigma-1)}{(\sigma+1)(\sigma-2)} \frac{E}{\rho}}
$$

in the direction of propagation of the selsmic shock.

Shear or transverse waves, which propagate perpendicular to the former at a velocity:

$$
v_{l}=\sqrt{\frac{G}{p}}=\sqrt{\frac{\sigma}{2(\sigma+1)} \frac{E}{p}}
$$

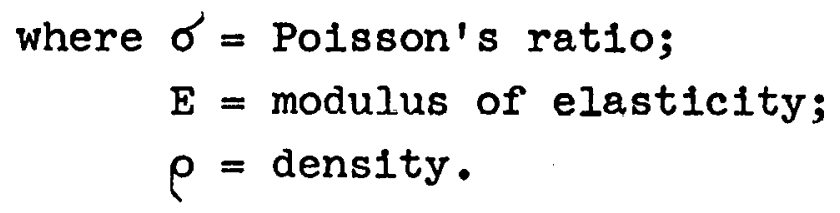

S-waves: do not propagate in liquids and in general we have:

$$
\frac{w}{2} \not 1,75
$$

But the earth is a finite medium

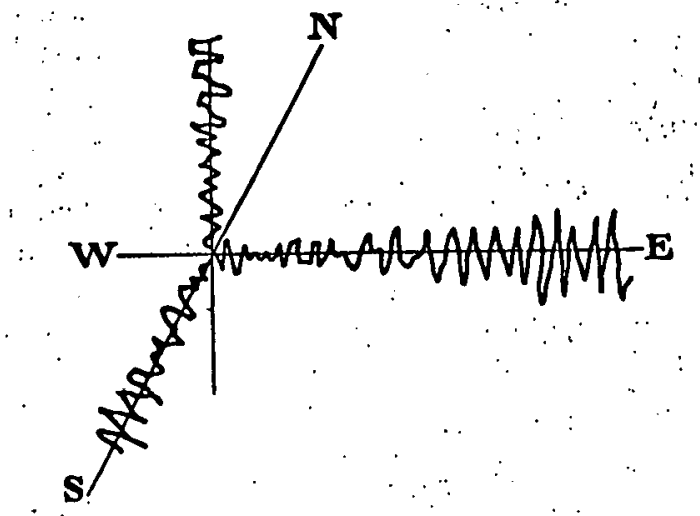

Fig. 1. limited by a surface. When the waves originating from the focus arrive at the earth's surface, they are subjected to the effects of discontinuities which they encounter. Two types of waves are then generated:

Rayleigh waves originating from the discontinuity of the medium in

which the S- and P-waves travel. They travel along the surface and generate vibrations on elliptical trajectories. They produce a change of volume, 1.e. deformations, and have the character of compressional waves. The ellipse on which a point of the earth's surface vibrates under the influence of this wave is normal to the direction of travel and the point has a velocity in the order of $0.9 v_{t}$. 
Love waves originate from a sharp change in the travel time of the transverse wave. These are surface waves acting in the plane tangent to the surface transversely with respect to the direction of propagation.

When the S- and P-waves encounter a discontinuity of the elastic medlum or the surface, they are reflected or refracted. A longltudinal wave which does not arrive normal to the surface of the boundary generates a longitudinal reflected wave and a transverse reflected wave; thus, the deformation on the axis of propagation is decomposed into a normal and a transverse deformation in the direction of reflection.

B. Effects of Earthquakes

A measurement of the destructive effects of an earthquake is highly inexact; in the language of specialists, it is expressed by the concept of the seismic intensity which covers numerous factors: effects on man and objects, damage of construction, and degree of damage of different structures. We thus realize the importance of an objective definition of the intensity of an earthquake.

Different scales have been proposed to characterize these intensities. The most common will be considered here:

1. Magnitude scale (Gutenberg-Richter).--On the basis of the concept that two earthquakes with the same hypocenter resulted in different intensities at the same site, we can deduce that an ele-. ment exists wh1ch characterizes the energy of the selsmic shock at Its focus (magnitude).

Following his research, Richter furnished a relation between the energy released at the focus of a selsmic shock and the magnitude:

$$
\log _{10} E=9,9+1,9 \mathrm{M}-0,024 \mathrm{M}^{2}
$$


where $E=$ energy expressed in erg at the focus;

$\mathrm{M}=$ magnitude.

On the basis of this relation, Profs. D. E. Hudson and G. W. Housner, formulate a relation between the velocity spectrum $s$, and the energy released at the focus.

If $D$ is the distance from the epicenter and $M$ is the depth of the hypocenter, $s_{10}$ being the epicentral velocity spectrum, we have:

$$
\begin{aligned}
S_{10} & =S_{1}\left[i+\frac{D}{H}\right]^{2} \\
\text { and } E & =C S_{10}^{3}
\end{aligned}
$$

where $\mathrm{C}$ is a coefficient to be determined experimentally.

Thus, transformed, the relation of Richteribecomes:

$$
\begin{gathered}
0,054 M^{2}-2,14 M+9,88-2 \log _{10} S_{10}=0 \\
\text {-with } M \leqslant 8.9
\end{gathered}
$$

2. Spectral intensity scale (G. W. Housner).--On the basis of the concept that the characteristics of an earthquake can be recorded by a seismograph and that the relation between the characteristics of the accelerogram of the seismic shock and the damage caused to construction can be determined experimentally on dynamic models, G. W. Housner has proposed the following method:

He imposes the displacements furnished by the seismograph on a vibrating mass with a natural period of between 0.1 and $2.5 \mathrm{sec}$, and he records the maximum amplitude and maximum velocity for different damping factors $\downarrow$.

By plotting the results on a diagram ( $\max$. amplitude-T) or (max. velocity-T) for the same earthquake, the response or earthquake spectrum is obtained (Fig. 2).

3. Spectral action scale (Medvedev).--Prof. S. V. Medvedev of the USSR introduced the concept of the "action spectrum" X in 1953 defined by: 


$$
X(t)=X_{0} \psi(T)=(8)
$$

$x_{0}$ is an element which characterizes the seismic intensity measured by the displacement amplitude of a pendulum with a natural period $T_{0}=0.25 \mathrm{sec}$ and with damping defined by the logarithmic decrement $\delta=0.50$.

$\psi(T)$ is a spectral function depending on the natural oscillation period of the type of construction:

$\begin{array}{ll}\text { For } 0.1 \mathrm{~s}<\mathrm{T}<0.5 \mathrm{~s} & \psi=\mathrm{T}^{2} / \mathrm{T}_{0}^{2} \\ \text { For } 0.5 \mathrm{~s}<\mathrm{T}<1.5 \mathrm{~s} & \psi=2 \frac{\mathrm{T}}{\mathrm{T}_{0}}\end{array}$

and for $1.5 \mathrm{~s}<\mathrm{T}<2.5 \mathrm{~s} \quad \psi=12$

$\varepsilon(\delta)$ is a function which represents the damping of the structure:

$$
c(8)=\frac{1}{\sqrt{28}}
$$

The curves of Figs. 3, 4 and 5 define these various functions.

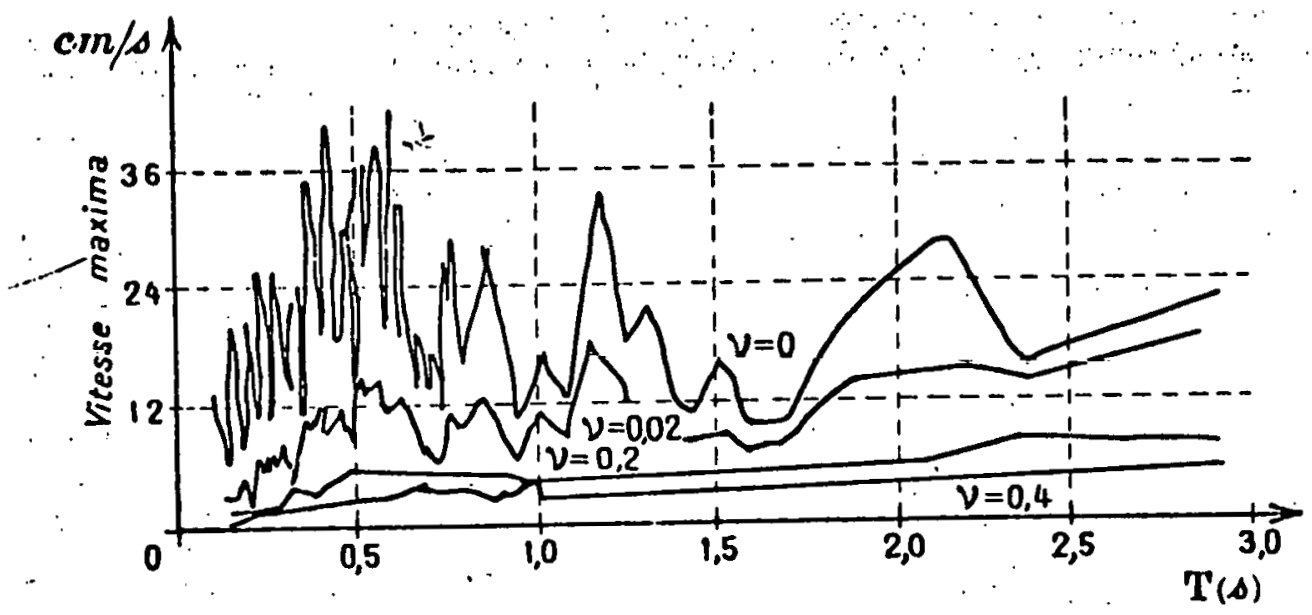

Max。 velocity

Fig. 2.--Velocity spectrum for the El Centro earthquake of 1940 .

Sefsmic scale degree FIg. 3

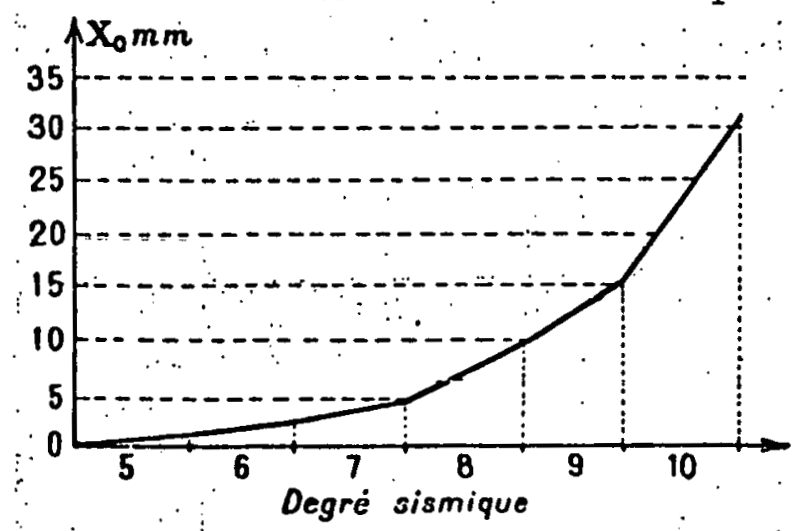




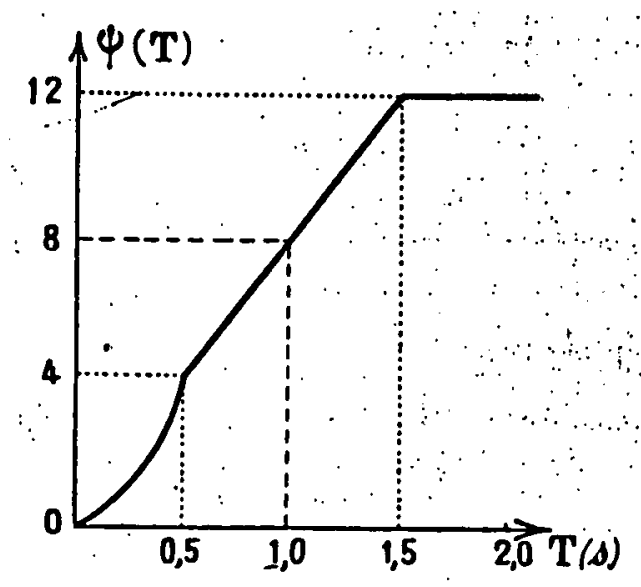

Fig. 4.

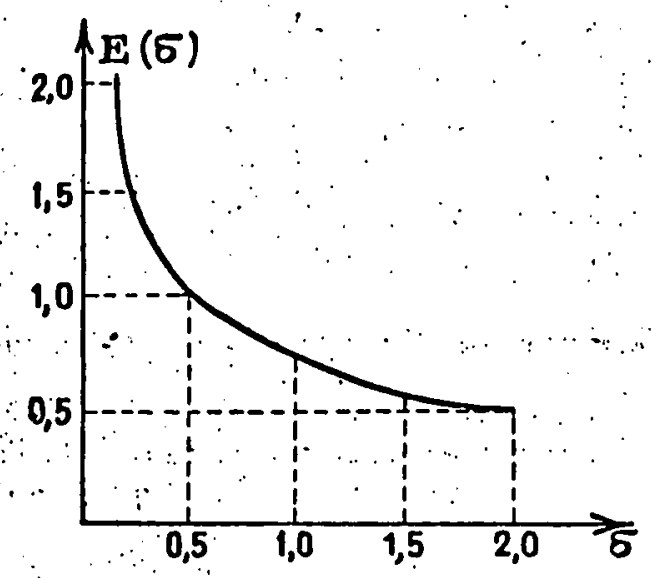

Fig. 5.

4. Relation between the seismic intensity scales.-- It is necessary to interrelate the different scales. We have not yet spoken of the "Modified Mercalli Scale" of Ch. F. Richter of 1956 which classifies earthquakes on the basis of damage caused to buildings; it can be defined by the relation:

$$
\log _{10} a=\frac{1}{3}-\frac{1}{2}
$$

where $a=$ acceleration in $\mathrm{cm} / \mathrm{s}^{2}$;

I = intensity represented by the grades corresponding to the Modified Mercalli Scale.

We thus obtain the following table:

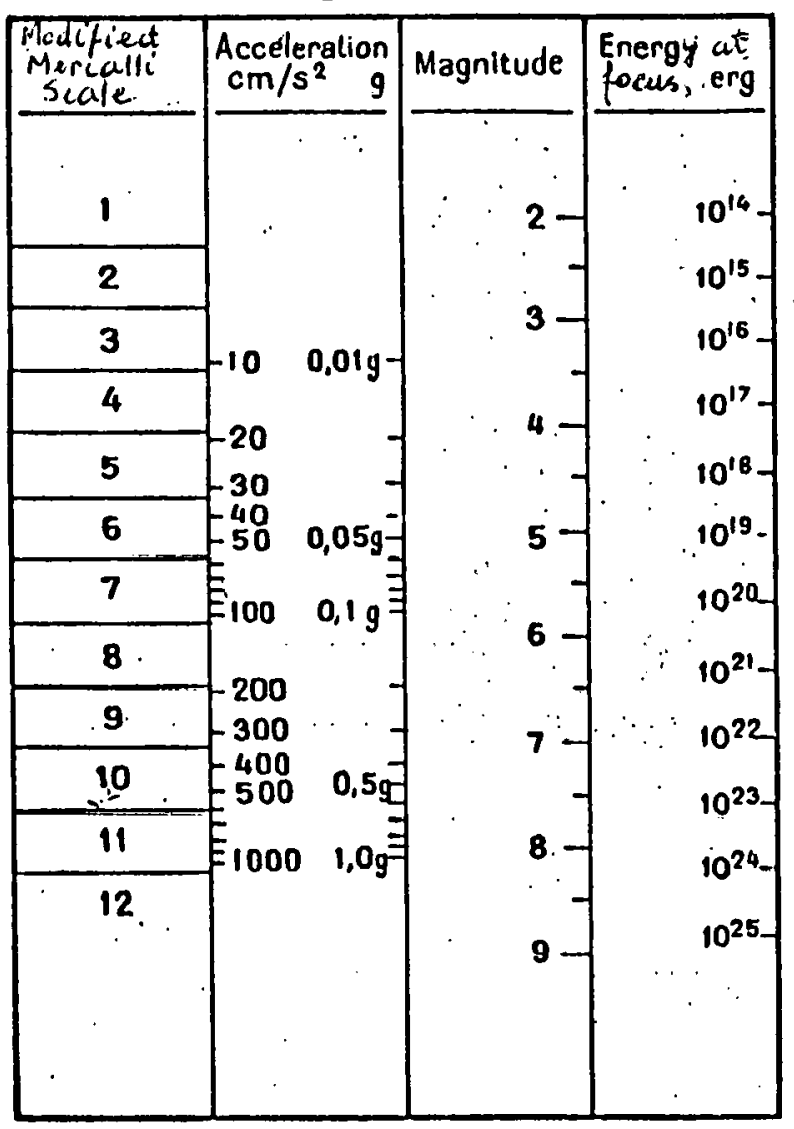


5. Variation of the intensity with the distance from the epicenter.--It is of interest to know how the intensity of a seismic shock varies with its distance from the epicenter.

Frank Neumann plotted the diagram of Fig. 6 following his research in 1952.

It is evident that granite is the foundation which attenuates seismic shocks best, while unconsolidated solls have little influence on the attenuation of the shock.

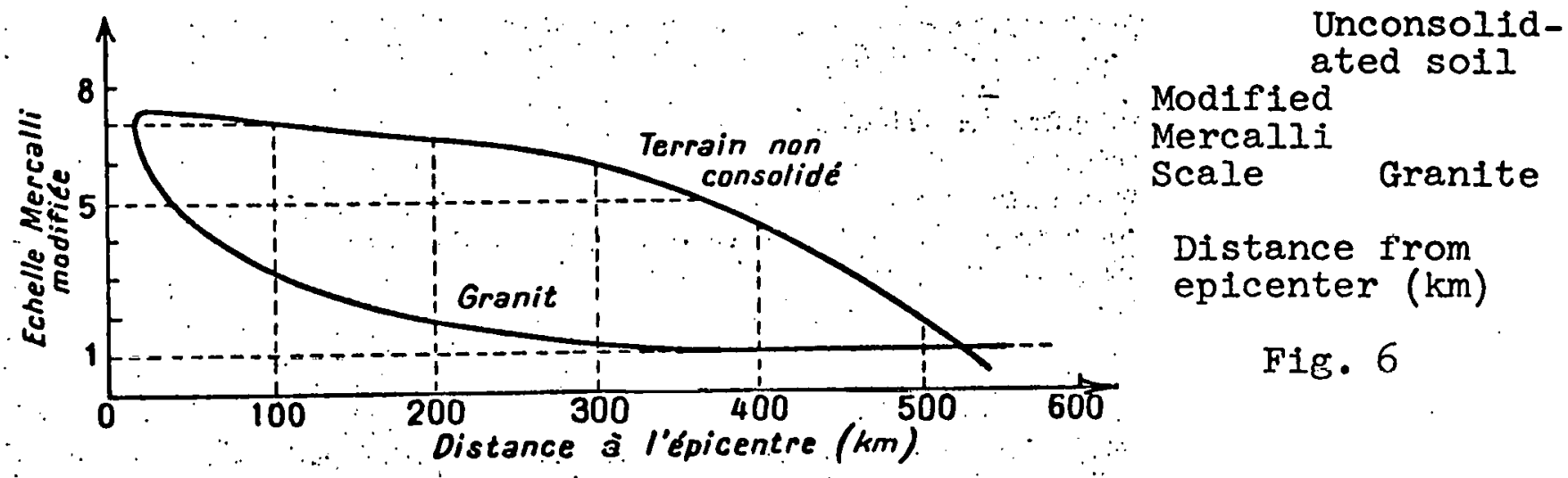

\section{Chapter II--Harmonic Analysis of Seismic Stresses}

From the standpoint of the engineer who designs bullalngs, a selsmic shock takes the form of a sequence of acceleration pulses at the base of the structure with a varied intensity and duration.

We have seen that the intensity is the basis for different seismic scales.

The work of Prof. G. W. Housner and of the Canadian engineer, G. N. Bycroft (based on the investigations of pulses from a white noise) showed that dominant frequencles do not exist during a seismic stress.

At the Lisbon National Civil Engineering Laboratory (LNEC), analytical studies have been carried out which deal with various linear oscillators subjected to real or fictional seismic spectra and the results obtained are in agreement with those of Housner and Bycroft. 
Following these studies, we will attempt to characterize seismic shocks 。

A. Intensity Distribution of the Seismic Acceleration

The studies of Bycroft assumed that the seismic shock had a untform spectral density, leading to the conclusion that the acceleration distribution was Gaussian.

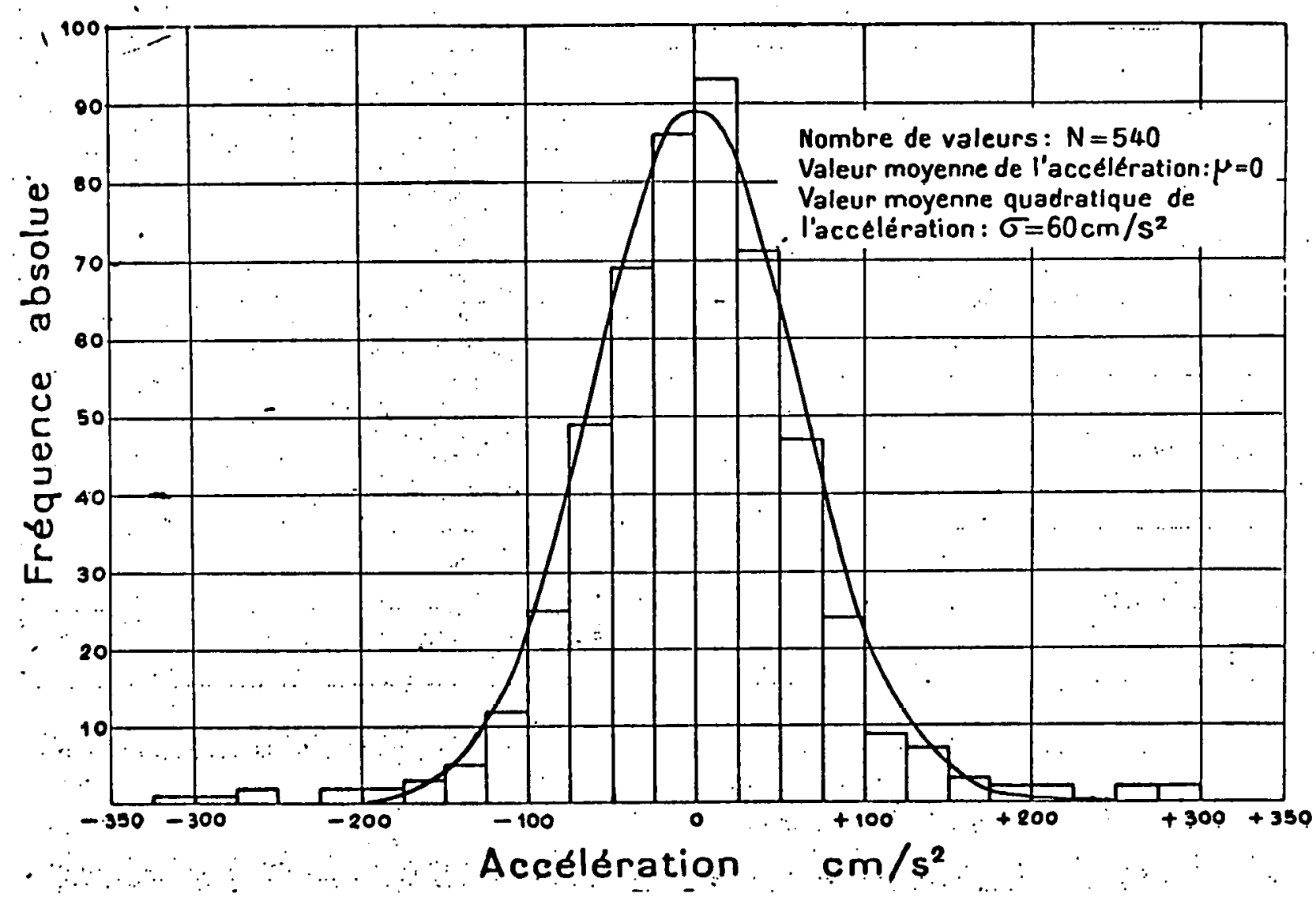

Absolute frequency

Acceleration $\mathrm{cm} / \mathrm{s}^{2}$

Number of values: $N=540$

Mean value of acceleration: $\mu=0$.

Mean square value of acceleration: $\sigma=60 \mathrm{~cm} / \mathrm{s}^{2}$

Fig. 7.--El Centro earthquake, 18 May 1940 (N-S). Comparison of the histogram of the acceleration frequencies to the Gaussian curve. 
If we start with the accelerogram of the $\mathrm{N}-\mathrm{S}$ component of the El Centro earthquake of 18 May 1940 which had a perlod of $25 \mathrm{sec}$, we will attempt to evaluate the characteristics of the acceleration distribution.

The accelerogram has the following characteristics:

Mean value of acceleration: $M=0$.

Mean square value of acceleration: $\sigma=60 \mathrm{~cm} / \mathrm{s}^{2}$

Number of values of the accelerogram: $N=540$.

Accelerogram interval $\Delta t=0.05 \mathrm{sec}$.

The frequency histogram represented by the curve of Fig. 7 fits very well on a Gaussian curve. Moreover, the $X^{2}$-test shows that the accelerations have indeed a Gaussian distribution.

In view of the analogy of different earthquakes as demonstrated by Prof. G. W. Housner, it is logical to consider the accelerogram of a given earthquake to be representative of the general phenomenon of seismic stresses; and thus to consider the two components of the same earthquake to be independent.

\section{B. Spectral Analysis of Selsmic Stresses}

The study was carried out by the LNEC on the basis of four accelerograms relative to four strong earthquakes recorded in Callfornia, the characteristics of which are given in the table below [see p. 10].

These accelerograms furnish maximum acceleration values at Intervals of about $0.05 \mathrm{sec}$.

The power spectra were calculated on the computer of this laboratory.

The results are given in the graph of Fig. 8 .

We can observe large amplitude fluctuations of the spectral density as well as a very rapid decay of the latter as soon as the frequency is higher than $5 \mathrm{~Hz}$. 
Earthquake

Distance Depth Magni- Max. Dura-
from epicenter focus tude accel. tion

\begin{tabular}{|c|c|c|c|c|c|c|}
\hline . stiomo $\quad \therefore \quad$. & & $\begin{array}{c}\text { Distance } \\
\text { do } \\
\text { P'épicentre }\end{array}$ & $\begin{array}{l}\text { Prolondeur } \\
\text { du foyer }\end{array}$ & Magnitude & $\begin{array}{l}\text { Accél. } \\
\max .\end{array}$ & Durée \\
\hline $\begin{array}{c}5-18-1.940 \\
\text { El Centro, } 18-5.1940 \ldots \ldots \ldots \ldots \ldots \ldots .\end{array}$ & N.S & $\begin{array}{l}\mathrm{km} \\
48\end{array}$ & $\begin{array}{l}\mathbf{k m} \\
24\end{array}$ & 6,7 & $\begin{array}{c}\mathrm{cm} / \mathrm{s}^{\circ} \\
330\end{array}$ & 30 \\
\hline $\begin{array}{lll} & \therefore & \cdots\end{array}$ & E-W & 48 & $\because 24$ & 6.7 & 230 & 30 \\
\hline $\begin{array}{r}12-30-1934 \\
\text { El Centro, 30-12-1934..... }\end{array}$ & N.S & 56 & 24 & 6,5 & 255 & 25 \\
\hline & E.W & 56 & 24 & 6,5 & 196 & 25 \\
\hline $\begin{array}{c}7-21-1952 \\
\text { Taft, } 21-7-1952 \ldots \ldots \ldots \ldots\end{array}$ & N21E & 64 & 24 & 7,7 & 170 & 30 \\
\hline- & N69W & 64 & $\cdots 24$ & 7.7 & 180 & 30 \\
\hline $\begin{array}{r}4-13-1949 \\
\text { Olympia, } 13.4 .1949 . \ldots .\end{array}$ & N80E & 72 & 72 & $.7,1$ & 310 & 30 \\
\hline . & N10W & 72 & 72 & 7,1 & 180 & 30 \\
\hline
\end{tabular}

From power spectra, we easily obtain the mean square value $\sqrt{a^{2}}$ of the acceleration. If $S(f)$ is the spectral density corresponding to the frequency $f$, we have:

$$
\overline{a^{a}}=\int_{0}^{\infty} S(f) d f
$$

Thus, $\bar{a}^{2}$ is represented by the area bounded by the curve $S(f)$ and the frequency axis.

We obtain the following results:

\begin{tabular}{|c|c|c|c|c|c|c|c|c|}
\hline \multirow{2}{*}{ Earthquake } & \multicolumn{2}{|c|}{ El Contm $5 \cdot 18-1840$} & \multicolumn{2}{|c|}{ EI Centro $12 \cdot 30 \cdot \because \cdot 1934$} & \multicolumn{2}{|c|}{ Talt $)-24-1052$} & \multicolumn{2}{|c|}{ Olympia $: /-13-1040$} \\
\hline & $\mathbf{N}-\mathbf{S}$ & E-W & N-S & $\mathbf{E}-\mathbf{W}$ & N21E & NGow & N8OE & Niow \\
\hline Variance, $\mathrm{cm}^{2} \mathrm{~s}^{-4}$. & 3.820 & 2.690 & 1.900 & 2.305 & 1.360 & 1.775 & 2.930 & 2.190 \\
\hline Mean square value, $\mathrm{cm}^{-2}-$. & 61,8 & 51,7 & 43,4 & 48,0 & 36.7 & 42,0 . & $54,0^{\circ}$ & 46,6 \\
\hline $\begin{array}{l}\text { Equivalence } \\
\text { coeffleient, } \alpha . \cdot\end{array}$ & 1,00 & 1,42 & 2,01 & 1,66 & 2,81 . & 2,15 & 1,30 & $1 ; 74$ \\
\hline
\end{tabular}


SPECTRE DE PUISSANCE DE LA COMPOSANTE N-S DU SÉISME DE. EL CENTRO (18 mal 1940)

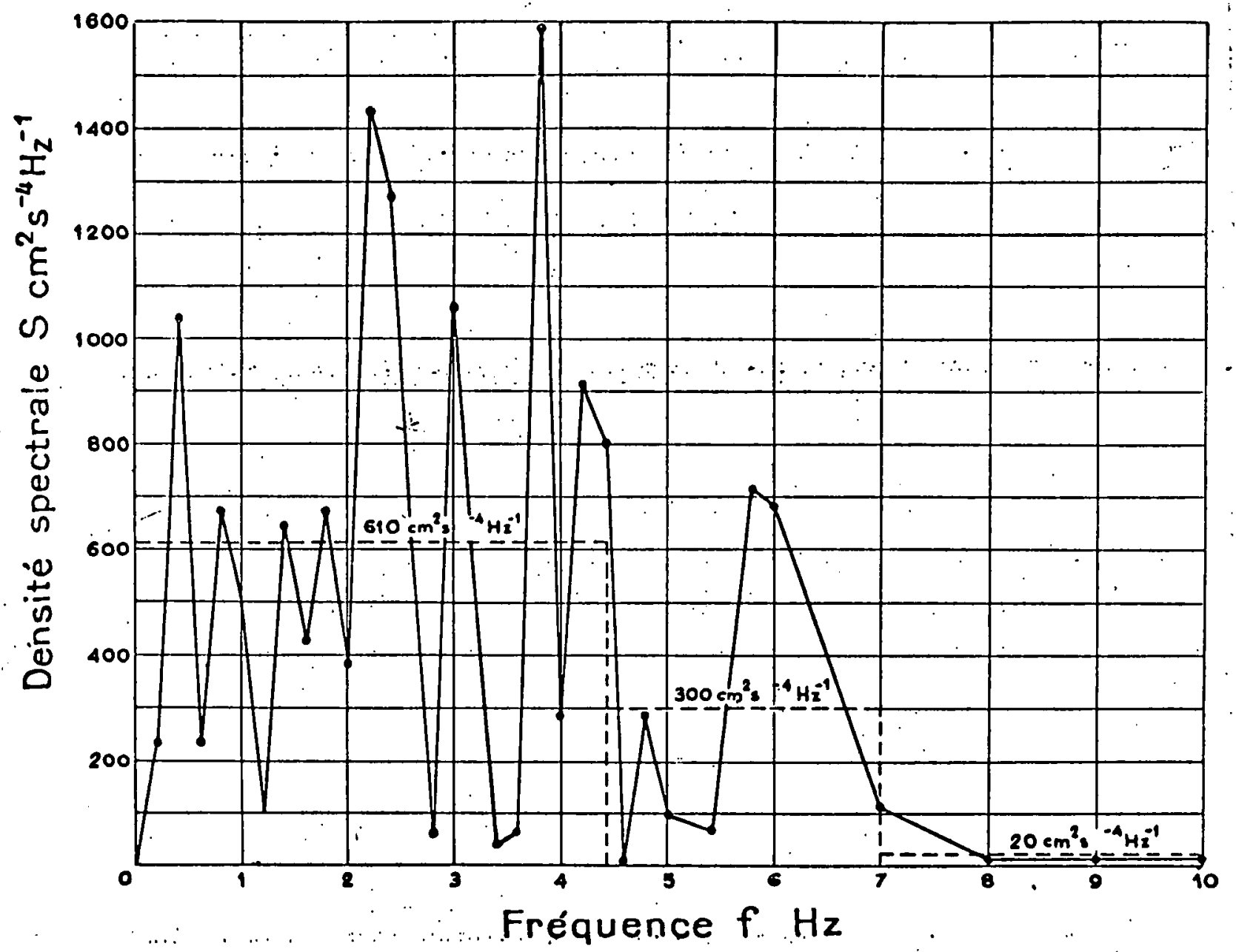

Spectral density $S$

Frequency $f, \mathrm{~Hz}$

F1g. 8.--Power spectrum of the $\mathrm{N}-\mathrm{S}$ component of the El Centro earthquake (18 May 1940).

If we reduce the power spectra as calculated to the same value of the variance, using the weakest earthquake as the reference, we must multiply the values of the spectral density by the coefficient $\alpha$ defined in the above table.

Taking the mean of densities for each value of the frequency, we thus obtain the mean spectrum represented in the graph of Fig. 9. We find the following characteristics in this spectrum:

The energy content is limited practically to the interval of $0-5 \mathrm{~Hz}$ with a maximum in the range of $2-3 \mathrm{~Hz}$. 
SPECTRE DE PUISSANCE MOYEN RÉDUIT A L'INTENSITÉ dU SÉISME dE EL CENTRO (N-S) 18 MAI 1940

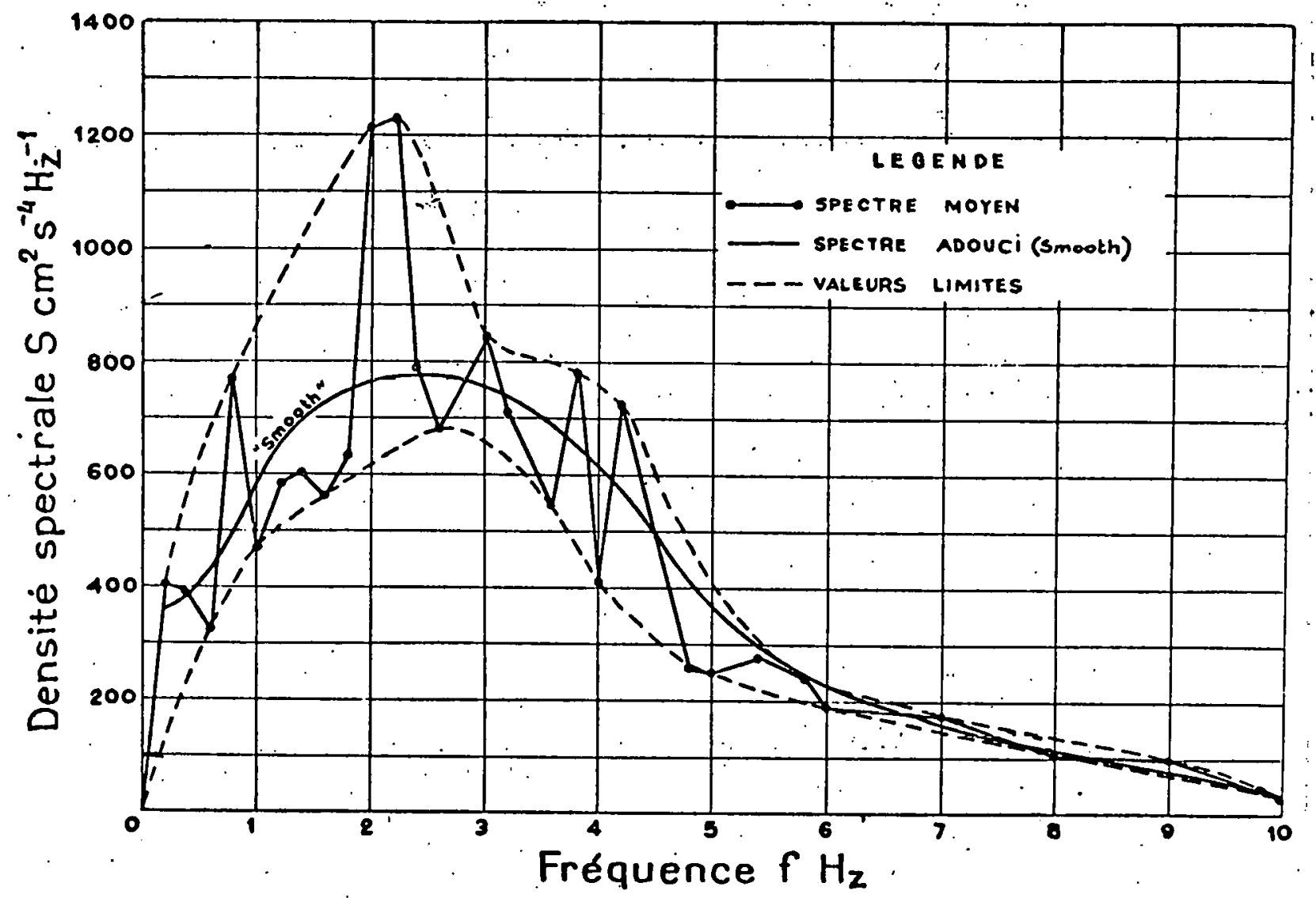

Spectral density $S$

Frequency $\mathrm{f}, \mathrm{Hz}$

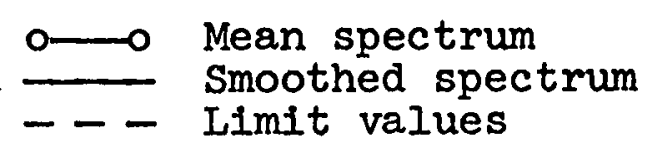

Fig. 9.--Mean power spectrum reduced to the intensity of the E1 Centro Earthquake (N-S) (18 May 1940).

In this range, the fluctuations are particularly evident (we neglected the very much smaller values of spectra of different accel.erograms).

C. Comparison with Existing Results

Prof. G. W. Housner has characterlzed four earthquakes analyzed by coefficients which related the maximum values of the acceleration, the velocity and the displacement of stressed linear oscillators. 
These coefficlents can be easily related to the spectral densities. Thus, if we consider an oscillator of frequency $2 \pi / \omega_{0}$, damping $\eta$, subjected to an earthquake of spectral density $s_{0}$, and if $x$ is the displacement, we have the relation:

$$
x^{2}=\frac{9 S_{0}}{8 \eta \omega_{0}^{3}}
$$

When we consider the same oscillator subjected to earthquakes of density $s_{1}$ and $s_{2}$, we have:

$$
\left(\frac{x_{1}}{x_{8}}\right)^{2}=\frac{S_{1}}{S_{8}} .
$$

1.e.

$$
\frac{s_{1}}{s_{2}}=\sqrt{\bar{S}_{2}} .
$$

The Housner coefficlents thus are proportional to the square roots of the spectral densities.

If we consider the mean value of the spectral density in the frequency band investigated by Housner $(0.36-2.50 \mathrm{~Hz})$ for the four

\begin{tabular}{|c|c|c|}
\hline Earthquake & $\begin{array}{l}\text { Sque } \\
\text { spec }\end{array}$ & $\begin{array}{l}\text { root of } \\
\text { ral density }\end{array}$ \\
\hline$\because \quad \begin{array}{c}\text { seismo } \\
\vdots\end{array}$ & $\begin{array}{l}\text { Coomcient } \\
\text { do Houenor }\end{array}$ & $\begin{array}{l}\text { Pacino carréo } \\
\text { ao la donuliso opectralo }\end{array}$ \\
\hline El Centro, $5-18-1.940 \ldots \ldots \ldots \ldots$ & 2,7 & 2,60 \\
\hline El Centro, $1.2-30-1934, \ldots \ldots \ldots \ldots$ & . 1,9 & 1,90 \\
\hline Taft, $7-21-1952 \ldots \ldots \ldots \ldots \ldots \ldots$ & 1,9 & 1,83 \\
\hline Olympia, 4-13-1939........ & $1,60^{\circ}:$ & 1,70 \\
\hline
\end{tabular}
analyzed earthquakes, we obtain the values of the table below which we compare to those of Housner:

We find indeed that the coefficients thus defined have values very similar to those given by Housner. 
If we now compare the value of the mean spectral density calculated from the mean spectrum in the same frequency band $0.36-$ $2.50 \mathrm{~Hz}$ ), the mean spectral density being

$$
S_{1}=689 \mathrm{~m}^{2} \mathrm{~s}^{-4} \mathrm{H} z^{-1}
$$

with that given by Bycroft, which is

$$
\mathrm{S}_{\mathrm{z}}=697 \mathrm{~cm}^{2} \mathrm{~s}^{-4} \mathrm{~Hz}^{-1}
$$

we find that these values are nearly identical.

In conclusion, we can say that the intensity distribution of the accelerogram is Gaussian; during an earthquake, the energy distribution falls into a limited frequency band $(0-5 \mathrm{~Hz})$ with a maximum near 2-3 $\mathrm{Hz}$; it is of great interest to continue the spectral analysis of accelerograms so as to confirm the shape of the mean power spectrum.

\section{Footnote}

1) This study has been presented as "personal research" by the author while he was a student at the National College of Bridges and Roads. Its realization benefited from support and encouragement of the Lisbon National Civil Engineering Laboratory as well as the Technical Exchange Fund to whom the author expresses his appreciation. 


\section{PART II}

\section{DYNAMICS OF SYSTEMS WITH $\mathrm{n}$ DEGREES OF FREEDOM}

\section{Free Oscillations of Systems with $\mathrm{n}$ Degrees of Dynamic}

\section{Freedom}

In the following, we are investigating the free oscillations of systems with $\mathrm{n}$ degrees of freedom which in practice permit a determination of the natural frequency spectrum and thus of the natural forms of vibrations.

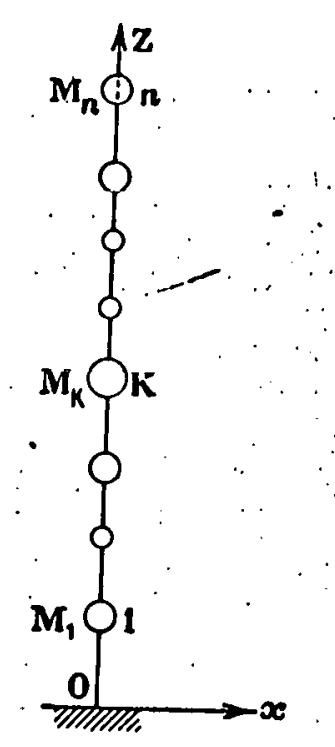

Fig. 10.

In the calculation of frequencles and of natural forms [sic.], we will neglect the effect of damping because we can neglect $\nu^{2}$ with respect to unity.

The type of system corresponds to that of a building in which the floors are much more rigid than the studs (Fig. 10).

Let $m_{1}$ be the mass of the flooring 1 ;

$\mathrm{K}_{1 \mathrm{f}}$ is the rigidity at point 1 of the system which is defined as the force generated at point 1 when point $f$ is displaced by $x J=1$ with:

We define:

$$
x \neq j=0
$$

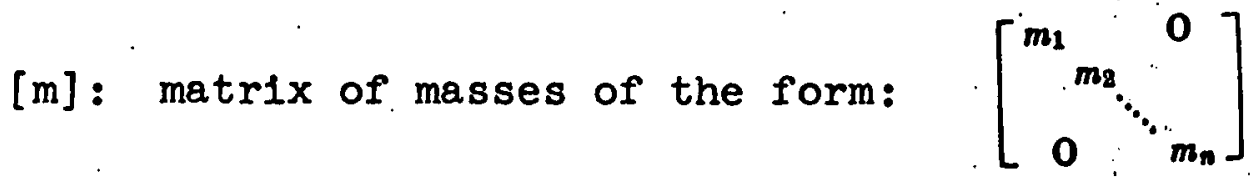

[x]: displacement vector of masses with respect to the ground;

$[\mathrm{K}]:\left[\mathrm{K}_{1 \mathrm{f}}\right]$ rigidity matrix.

The equation of motion is:

$$
[m]\left|x^{n}\right|+[\mathrm{K}]\{x \mid=0 .
$$

We assume solutions in the form of: $|x|-A|\varphi| \sin \omega t$ 
where $2 \pi / \omega$ is a natural frequency, and $A\{\varphi\}$ is an amplitude. We have:

1.e: $\left.-\omega^{2}[m] A \mid \varphi\right\} \sin \omega t+[K] A\{\varphi \mid \sin \omega t=1)$ $\left[[\mathbf{K}]-\omega^{2}[m]\right]|\varphi|-|0|$

This is a homogeneous system of Inear equations. So as not to have the solution $\{\varphi\}=\{0\}$, we must have:

$$
[\mathrm{K}]-\omega^{2}[\dot{m}]=0
$$

This defines the natural frequencies $2 \pi / \omega$ with the number of $n$.

For each value of $\omega$, we have $n$ corresponding values of $\varphi$ which characterize a mode of oscillations (or natural form of vibrations).

We thus define an ensemble of $n$ natural frequencies $\left\{2 \pi / \omega_{1}\right\}$ and an ensemble of $n$ modes of oscillation corresponding to each column of the matrix:

$$
[\varphi]=[\varphi(y]
$$

for each structure.

We therefore have: number of degrees of freedom $=$ number of natural frequencies $=$ number of oscillation modes.

Chapter II--Forced Vibrations of Systems with $n$ Degrees of Dynamic Freedom Due to a Seismic Shock

We consider that the seismic shock consists of a series of random pulses of the acceleration transmitted to the structure by the ground; $U_{0}^{\prime \prime}(t)$, which we assume to be analytically known.

We must define the spectral density of the wave as a function of the frequency. We have seen that it varies with the frequency. It has in fact been demonstrated that the maximum average displacement values for a linear oscillator and an elastic-plastic oscillator hardly depend on the shape of the spectral density curve but primarily 
on the mean value of the spectral density in the usual frequency field considered $(0-8 \mathrm{~Hz})$.

We will therefore use a spectral density of $s_{0}=$ constant.

A. System with One Degree of Freedom (Fig. 11)

We have the differential equation:

1.e.:

$$
M \frac{d^{2} \mathrm{Z}}{d t^{2}}+\beta \frac{d Z}{d t}+K Z=-M_{0}^{*}(t)
$$

$$
\frac{d^{2} Z}{d t^{2}}+2 \varepsilon \frac{d Z}{d t}+\omega^{2} Z=-U_{0}^{\prime \prime}
$$

with

$$
\varepsilon=\frac{\beta}{2 M} \quad \omega^{2}=\frac{K}{M}
$$

This furnishes the solution:

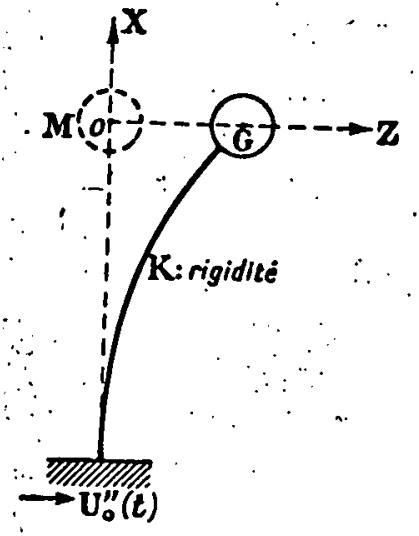

Rigidity

$$
Z=e^{-v a t} A \cos \left(\omega \sqrt{1-v^{2}} t-\varphi\right)+\frac{1}{\infty \sqrt{1-v^{2}}} \int_{0}^{i} U_{0}^{0}(t) e^{-\infty}(t-\tau) \sin \omega \sqrt{1-v^{2}}(t-\tau) d \tau \quad \text { FIg. } 11
$$

By definition, the integral is the velocity spectrum $S_{v}$, i.e.:

$$
S_{v}=\int_{0}^{t} U_{0}^{0}(\tau) e^{-v \omega(t-\tau)} \sin \omega \sqrt{1-v^{2}}(t-\tau) d \tau
$$

Since damping is very rapid, we can neglect the first term of $z$ and we thus have:

We can write:

$$
\mathrm{Z}=\frac{1}{\omega \sqrt{1-v^{2}}} S_{v}
$$

$$
S_{v}=\int_{0}^{t} U_{0}^{*}(\tau) h(t-\tau) d \tau
$$

where:

$$
h(t-\tau)=e^{-v \omega(t-\tau)} \sin \omega \sqrt{1-v^{2}}(t-\tau) d \tau
$$

Is the response of the oscillator at time t to the unit pulse transmitted at time $\tau$. 
B. Systems with n Degrees of Freedom. (FIg. 12)

The differential equation of motion at

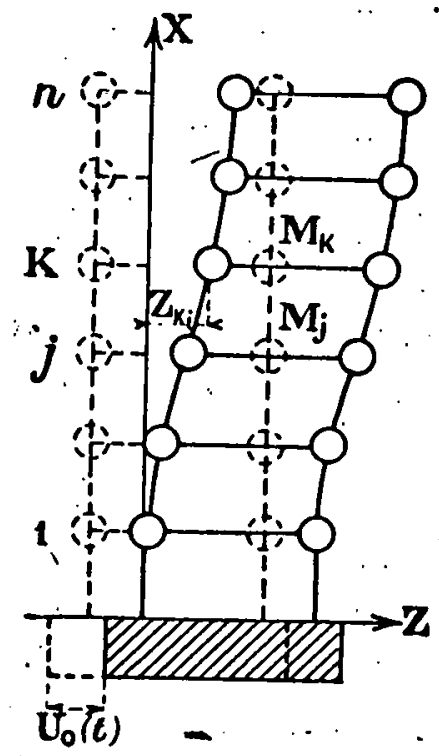

Fig. 12. point $\mathrm{K}$ is :

$$
M_{k} \frac{d^{t}}{d t^{g}}\left[Z_{k}(t)+U_{0}(t)\right]+\beta_{k} \frac{d Z_{k}(t)}{d t}+\sum_{j=1}^{n} K_{k j} Z_{f}(t)=0
$$

where $M_{k}=$ mass at point $k$;

$z_{k}(t)=$ real displacement of point $K$ with respect to the base in the direction of oscillation under the influence of the earthquake; $\beta_{1}=$ damping factor (Voigt hypothesis); $\mathrm{K}_{\mathrm{KJ}}=$ rigidity of the system at point $\mathrm{K}$.

Let:

$$
M_{k} Z_{k}^{*}+\beta_{k} Z_{k}+\sum_{i=1}^{n} K_{k j} Z_{j}=-M_{k} U_{0}^{*}
$$

We have a system of $n$ equations identical to that of a forced oscillator subjected to the function of time.

We let:

$$
Z_{k}(t)=\sum_{i=1}^{n} Z_{k+\varphi_{1}(t)}
$$

where $\phi_{1}(t)$ defines the elastic deformations of the structure in time.

We first determine a preliminary relation.

In the case of free vibrations, we had:

$$
M_{k} Z_{t t}^{n}+\sum_{k=1}^{n} K_{k j} Z_{s t}(t)=0
$$

For $z_{k 1}(t)$ we use a harmonic solution of the form of (2), 1.e.:

$$
\begin{aligned}
& Z_{k t}(t)=Z_{k t} \cos \left(\omega_{t} t+\theta_{l}\right) \\
& Z_{f t}(t)=Z_{j l} \cos \left(\omega_{t} t+\theta_{l}\right)
\end{aligned}
$$

We then have:

$$
\mathrm{M}_{k} \omega_{i}^{2} \mathrm{Z}_{k t}=\sum_{i=1}^{n} \mathrm{~K}_{k j} \mathrm{Z}_{j !}
$$


As a result of a change of variable (2), Eq. (1) is written:

$$
M_{k} \sum_{i=1}^{n} Z_{k t \varphi_{i}^{i}}+\beta_{k} \sum_{i=1}^{n} Z_{k i \varphi_{i}^{\prime}}+\sum_{i=1}^{n} M_{k} \omega_{i}^{2} \varphi_{l}=-M_{k} U_{i}^{i}
$$

1.e.

with

$$
M_{k}\left[\sum_{1} Z_{k i \varphi^{\prime}}+2 \varepsilon_{k} \sum_{l} Z_{k i} \varphi_{1}^{\prime}+\sum_{l} \omega_{i}^{2} \varphi_{l}\right]=-U_{0}^{*}
$$$$
\therefore \varepsilon_{k}=\frac{\beta_{k}}{M_{k}}
$$

We multiply this equation by $z_{k j}$ and form the sum from $k=1$ to $n$. We have:

$$
\sum_{k=1}^{n} Z_{k j} M_{k}\left[\sum_{i=1}^{n} Z_{k l}\left(\varphi_{i}^{i}+2 \varepsilon_{k} \varphi_{i}^{i}+\omega_{i}^{2} \varphi_{i}\right)\right]=-\sum_{k=1}^{n} M_{k} Z_{k j} U_{0}^{*}
$$

The orthogonalization condition of characteristlc forms implies that:

$$
\sum_{k=1}^{n} M_{k} Z_{k t} Z_{k j}=0\left\{\begin{array}{l}
1 \neq j \\
i, j \ldots-1,2 \ldots n
\end{array}\right.
$$

We assume that

$$
\text { regardless of } k
$$

We then have $n$ equations of the form:

$$
\sum_{k=1}^{n} M_{k} Z_{j j}^{2}\left(\varphi_{j}^{j}+2 \varepsilon \varphi_{j}^{j}+\omega_{j}^{2} \varphi_{j}\right)=-\sum_{k=1}^{n} M_{k} Z_{k j} U_{0}^{\prime}
$$

1.e.

$$
\varphi_{j}^{j}+2 \varepsilon \varphi_{j}^{j}+\omega_{j}^{2} \varphi_{j}=-\frac{\sum_{k=1}^{n} M_{k} Z_{k t}}{\sum_{k=1}^{n} M_{k} Z_{k j}} U_{0}^{o}
$$

We let:

$$
A_{f}(t)=-C_{j} U_{0}^{\prime \prime}(t)
$$

If the free oscillation which decays rapidly is neglected, we have:

$$
\Phi_{J}(t)=\frac{1}{\sqrt{\omega j-\varepsilon^{2}}} \int_{0}^{t} A_{1}(\tau) \varepsilon^{-\varepsilon(l-\tau)} \sin \sqrt{\omega_{j}^{2}-\varepsilon^{8}}(t-\tau) d \tau
$$


1.e.

$$
\underline{\underline{p}(t)=-\frac{C_{1}}{\omega \sqrt{1-v^{2}}} S_{v}} \text { with } c=v j \omega
$$

and therefore:

$$
\mathbf{Z}_{\mathbf{k}}=-\sum_{j=1}^{n} \frac{\mathbf{c}_{j}}{\omega, \sqrt{1-v^{\mathbf{a}}}} \mathbf{Z}_{\boldsymbol{k}} \mathbf{S}_{\mathrm{v}}
$$

We can make the approximation $\sqrt{1-v^{2}} \# 1$ because $v$ is in the order of 0.1 .

We let:

$$
a_{k t}=C_{1} Z_{k t}=\frac{\sum_{k=1}^{n} M_{k} \dot{Z}_{k t}}{\sum_{k=1}^{n} M_{k} Z_{t}} Z_{k t}
$$

and we will call this the form factor.

For the mode of vibration 1 , we can write the expressions of the following influences at the point $\mathrm{K}$ :

Displacement:

$$
Z_{k}(i)=\frac{a_{k l}}{\omega_{t}} \int_{0}^{t} U_{0}^{n}(\tau) e^{-\nu_{0} \omega_{1}(t-\tau)} \sin \omega_{t}(t-\tau) d \tau
$$

Velocity:

$$
Z_{k}^{\prime}(i)=a_{k t} \int_{0}^{t} \dot{U}_{0}^{\prime}(\tau) e^{-\nu_{1} \omega_{1}(t-\tau)} \cos \omega_{r}(t-\tau) d \tau
$$

Acceleration:

$$
Z_{k}^{*}(i)=\omega_{1} a_{k 1} \int_{0}^{t} U_{0}^{n}(\tau) e^{-v \theta_{1}(t-\tau)} \sin \omega_{t}(t-\tau) d \tau
$$

Force of inertia:

$$
F_{k}(i)=M_{k} \omega_{1} a_{k+1} \int_{0}^{t} U_{0}^{*}(t) e^{-v_{i} \omega_{1}(t-\tau)} \sin \omega_{1}(t-\tau) d \tau
$$

Total force at the base:

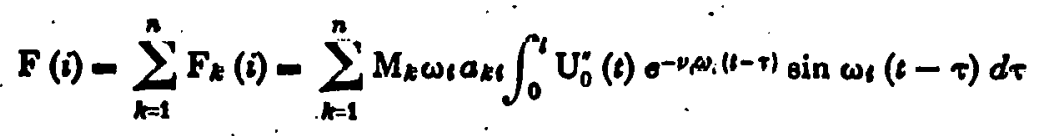

The form factor $a_{k 1}$ defines the dynamic response of point $K$ corresponding to the viluration mode 1 .

The form of the above expressions permits a complete analytical separation of the static and dynamic characteristics of the structure from the dynamic properties of the earthquake. 
In fact, we can write:

$$
\mathbf{R}_{k}(t)=\mathbf{R}_{k 1} \cdot \mathbf{R}_{k \mid 1} \text {. }
$$

where $R_{k}(t)$ is the dynamic response of the structure corresponding to the point $K$ to the seismic shock;

$R_{k I}$ represents the influence of the static and dynamic characteristics (specific for the type of structure) on the behavior of the structure;

$R_{k I I}$ represents the influence of the dynamic properties of the seismic wave (specific for the medium in which it travels) on the behavior of the structure.

Since a seismic shock is not periodic and has a transient character, it is evident that the maximum response will not be obtained by forming the sum of responses which correspond to each mode: this would lead to an overestimate of the response.

We can determine this maximum response by forming the quadratic mean of responses corresponding to each mode of vibration, i.e.:

$$
R_{k}(t)=\sqrt{\sum_{i=1}^{n} R_{i}^{2}(i)}
$$

$\frac{\text { C. Reduction of a System of } n \text { Degrees of Freedom }}{\text { to That with One Degree of Freedom }}$

We will show that the effect produced by an earthquake on a structure with $n$ degrees of freedom can be treated by means of a simple mass system.

A simple mass system can be made to correspond to any system of $n$ masses using the principles of energy and period equivalence (Figs. 13 and 14).

We can cal culate the reduced mass $\mathrm{Mr}$ of the pendulum which from the dynamic point of view represents the real structure with $\mathrm{n}$ masses.

For this purpose, we write the energy and natural frequency of vibration so that they are the same in both systems: 


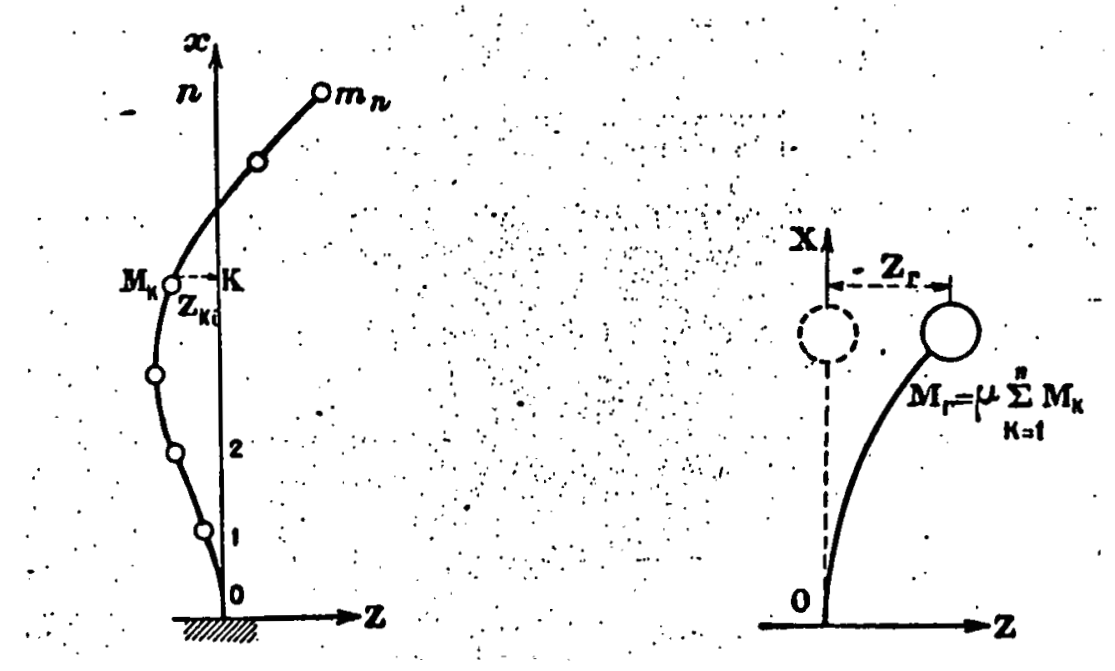

F1g. 13.--Real system FIg. 14.--Equivalent system.

$$
\begin{array}{ll}
P_{1}=P_{r} & \text { Rotential energy } \\
\omega_{r}=\omega_{r} & \text { Angular frequency } \\
W_{l}=W_{r} & \text { Kinetic energy }
\end{array}
$$

$$
\begin{aligned}
& P_{1}=P_{r} \text { is written as: } \\
& \frac{1}{2} M_{r} Z_{r}=\frac{1}{2} \sum_{h} M_{k} Z_{k l}
\end{aligned}
$$

$$
W_{1}=W_{r} \text { is written as: }
$$

$$
\frac{1}{2} M_{r} Z_{r}^{2}=\frac{1}{2} \sum_{k} M_{k} Z_{k 1}^{\prime}
$$

1.e.

$$
\omega_{i}^{2} M_{r} Z_{r}^{2}=\omega_{1}^{2} \sum_{k} M_{k} Z_{w 1}^{2}
$$

and $\omega_{1}=\omega_{r}$.

Therefore:

$$
\mathrm{M}_{\mathrm{r}} \mathrm{Z}_{r}=\sum_{k} \mathrm{M}_{k} \mathrm{Z}_{k i}^{2}
$$

from which:

$$
\sum_{k} M_{k} Z_{k i}^{2}=M_{r}\left(\frac{\sum_{k} M_{k} Z_{k t}}{M_{r}-}\right)^{i}
$$

and thus:

$$
M_{r}=\frac{\left[\sum_{k=1} M_{k} Z_{k t}\right]^{2}}{\sum_{k=1}^{n} M_{k} Z_{k t}}
$$


1.e.:

$$
\mu=\frac{M_{r}}{\sum_{k=1}^{n} M_{k}}=\frac{\left[\sum_{k 1}^{n} M_{k} Z_{k t}\right]^{8}}{\left[\sum_{k=1}^{n} M_{k}\right]\left[\sum_{k=1}^{n} M_{k} Z_{i t}\right]} \leqslant 1
$$

$$
\mu=\text { is the equivalence coefficient. }
$$

At the limit, $\mu=1$ for a system with one degree of freedom; the equivalence coefficient $\mu$ characterizes a system of $n$ degrees of freedom.

The equivalence coefficient can be written as a function of $a_{k 1}$ and we have:

$$
\mu=\underline{\sum_{k=1}^{n} M_{k}}
$$

This equivalence coefficient is used to obtain the various spectra $\mu S$, the seismic coefficients $\mu \mathrm{C}$ from those (S and $C$ ) which are determined in the case of the simple mass.

The total force at the base is:

$$
F(i)=M_{r} \omega_{i} S_{v}=\mu\left[\sum_{k} M_{k}\right] \omega_{r} S_{v}
$$

If we replace $\mu$ by Its value, we obtain the relation of Par. B. The force of inertia at level $K$ is obtained by:

$$
F_{k}(i)=F(i) \frac{M_{k} Z_{k 1}}{\sum_{k=1}^{n} M_{k} Z_{k t}}
$$

If we replace $F(1)$ by the value obtained above and $\mu$ by its value, we obtain the value of the expression $F_{k}(1)$ of Par. B.

This method of calculation of the total force at the base by the equivalent system and the distribution at each level of the construction has been adopted by the earthquake code in the U.S.A., Mexico, etc. and has proved very efficient. 
The method of calculation can be applied to the case of a construction with a distributed mass varying with height. The expressions are the same, but the integral sums are ehanged.

We have:

$$
M_{r}=\int_{0}^{L} \frac{m(x) Z^{2}(x) d x}{Z !}
$$

However, It is necessary to know an expression of the deformation $Z(x)$.

Chapter III--Calculation of Selsmic Forces in a Lattice Structure by the Method of Modal AnaIysis

We consider a lattice reinforced concrete structure composed of floors which are much more rigid than the studs (Fig. 16).

The deformation of a segment of the stud between two consecutive levels will be of the following type (Fig. 15).

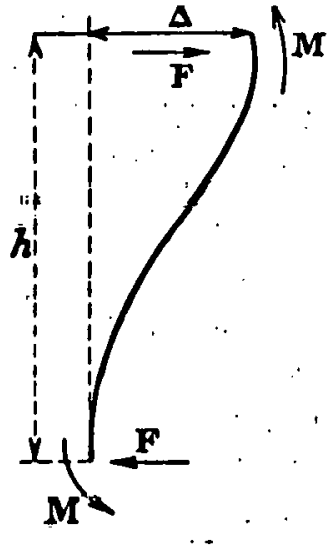

Fig. 15

If $\triangle$ is the relative displacement of two consecutive floors, we have:

$$
\begin{aligned}
& \dot{F}=\frac{12 E I \Delta}{h^{3}} \\
& M=\frac{6 E I \Delta}{h^{2}}
\end{aligned}
$$
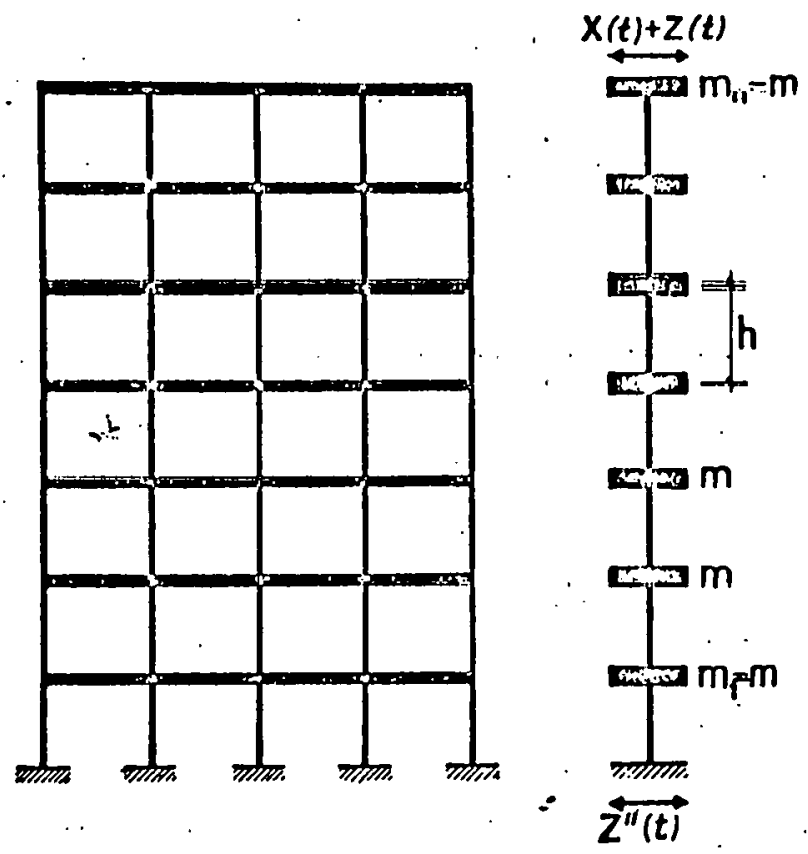

F1g. 16.--Investigated structure.

We consider that the studs support concentrated masses $m$ at 
the level of each floor which leads to an axlal compression at the stud base of $\sigma=50 \mathrm{~kg} / \mathrm{cm}^{2}$.

The height of the section of the stud between 2 floors is: $\mathrm{h}=3 \mathrm{~m}$.

The stud has a square cross-section with sides of $a=0.40 \mathrm{~m}$. The elastic modulus of reinforced concrete is $E=210,000 \mathrm{~kg} / \mathrm{cm}^{2}$.

The damping factor is $\forall=0.10$.

We assume that the seismic stress has a density $\mathrm{s}_{0}=675 \mathrm{~cm}^{2} \mathrm{~s}^{-4} \mathrm{H}_{3}^{-1}$ In the $0-8 \mathrm{~Hz}$ band.

The equation giving the displacement of the mass $m_{i}$ is:

$$
m_{1} x_{i}^{\prime}+\sum_{j=1}^{n} K_{i f x_{j}}=-m_{i} x^{*}
$$

where $K_{1 j}$ is the elastic restoring force at 1 when point $f$ is subject to a unit displacement.

We have:

$$
\begin{aligned}
& K_{u}=\frac{24 E I}{h^{3}} \\
& K_{1 j}=\frac{12 E I}{h^{3}} \text { thth } j=i+1 \\
& j=i-1 \\
& K_{1 j}=0 \quad \text { with } \quad \neq i \\
& \quad \text { or } t \neq i+1 \\
& \quad \text { or } i \neq i-1
\end{aligned}
$$

The [K] matrix then has the form:

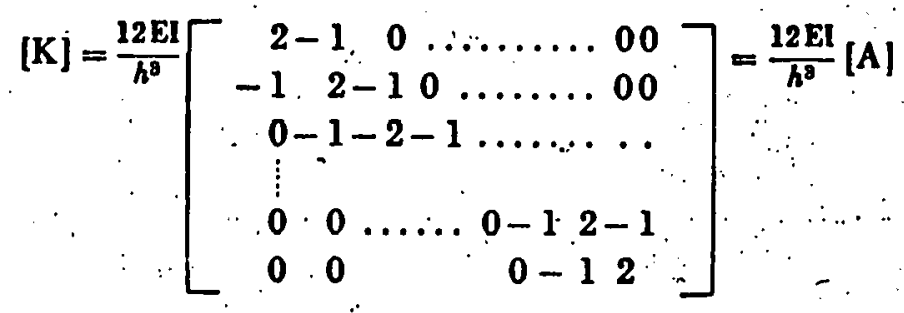

The fundamental equation of free vibrations becomes:

$$
\left[[\mathrm{K}]-\omega^{2}[(n])\right]=0
$$

1.e.

$$
[\mathrm{m}]=\mathrm{m}[\mathrm{I}] \text { and }[\mathrm{K}]=\mathrm{k}[\mathrm{A}]
$$

therefore:

$$
\underset{m}{k}[A]-\omega^{2}[I]=0
$$


The problem consists of determining the elgenvalues $\alpha$ of the $\operatorname{matrix}[\mathrm{A}]$ and of eigenvectors $\{\phi\}$.

We have:

$$
\begin{aligned}
& k=2.10^{4} \mathrm{~kg} / \mathrm{cm}^{2} \\
& m=\frac{80}{n} \mathrm{~kg}
\end{aligned}
$$

We will perform the detailed calculation for $n=2$; and for $\mathrm{n}=15$, we will give the results graphically.

We have: $m=40 \mathrm{~kg}$.

a) Eigenvalues and eigenvectors of $\mathrm{A}$. We have:

$$
\begin{gathered}
\alpha=\left\{\begin{array}{l}
0,38 \\
2,62
\end{array}\right\} \text { and } f=\left\{\begin{array}{l}
2,21 \\
5,78
\end{array}\right\} \text { because } \omega=\left\{\begin{array}{l}
13,8 \\
36,4
\end{array}\right\} \\
\cdots \quad[\varphi]=\left[\begin{array}{ll}
+0,62 & +1,00 \\
+1,00 & -0,62
\end{array}\right]
\end{gathered}
$$

b) Participation factor and generalized mass. In the case of forced oscillations, if we let $x(t)=[\varphi] E(t)$, the matrix calculation w1ll give:

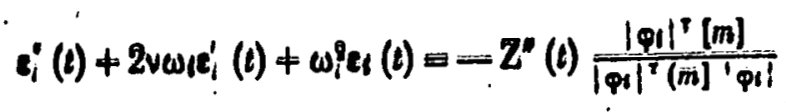

where $\varepsilon_{1}$ is the maximum displacement of an osciliator of fundamental frcquency aubjected to stress C1z",

$$
\begin{array}{ll}
\left\{\left.\Phi_{1}\right|^{[m]}\right. & \text { is the participation factor } R I, \\
\left.\mid \Phi_{1}\right\}^{\Gamma}[m]\left\{\Phi_{1}\right\} & \text { is the generalized mass } M i .
\end{array}
$$

We have: $\quad \frac{R_{1}}{M_{4}}=C_{1} ;[$ Ch II $-B]$

Here, we therefore have:

First mode:

$$
\left|\phi_{1}\right|^{p}[m]=1,62 \quad \longrightarrow \quad \frac{R_{1}}{M_{1}}=1,17
$$

Second mode:. In the same manner,

$$
\frac{\mathrm{R}_{\mathrm{i}}}{\mathrm{M}_{\mathrm{g}}}=0,28
$$


c) Amplitude of the equivalent oscillator. The mean quadratic value $\bar{x}^{2}$ of the amplitude of an oscillator of frequency $2 \pi / \omega_{0}$ and damping $\downarrow$ subjected to an earthquake with a spectral density so in the band $0-F$ containing $2 \pi / \omega_{0}$ is:

$$
t^{2}=\frac{S_{0}}{8 v \omega_{0}^{2}}
$$

Essentially, we have:

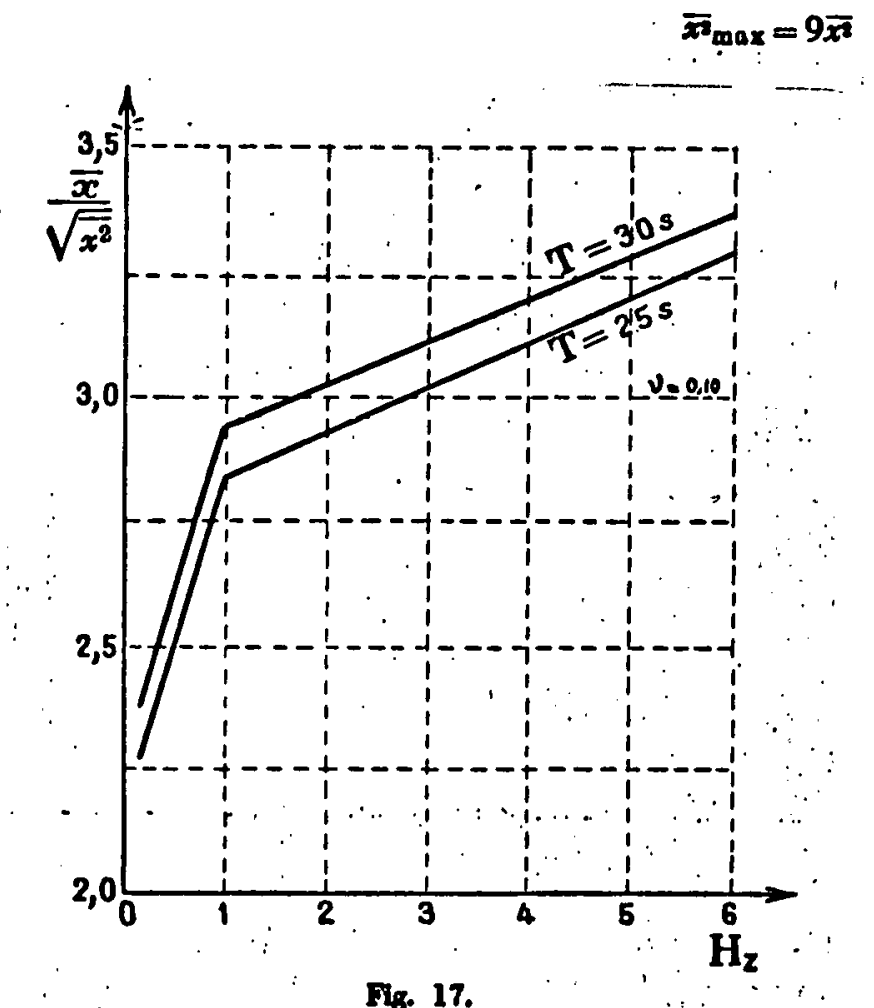

(see Fig. 17).

We therefore have:

$$
x_{\max }=\frac{87}{\sqrt{\omega_{i}^{*}}} \mathrm{~cm}
$$

The amplitude of the equivalent oscillator will be given by:

$$
\mu=\frac{R_{6}}{M_{1}} x_{\max }
$$

from which:

$$
\begin{aligned}
& c_{1}=1,17 \cdot \frac{87}{\sqrt{15,8^{3}}}=1,96 \mathrm{~cm} \\
& c_{2}=0,275 \cdot \frac{87}{\sqrt{36,4^{3}}}=0,11 \mathrm{~cm}
\end{aligned}
$$

d) Displacement amplitude. We have:

$$
\left\{x_{i}\right\}=i \varphi i^{i} i t i:
$$

so that,

First mode:

$$
\begin{aligned}
& \chi_{11}=1,96 \times 0,62=1,22 \mathrm{~cm} \\
& x_{21}=1,96 \times 1,00=1,96 \mathrm{~cm}
\end{aligned}
$$

Second mode:

$$
\begin{aligned}
& x_{12}=0,11 \times 1,00=0,11 \mathrm{~cm} \\
& x_{22}=0,11 \times(-0,62)=-0,068 \mathrm{~cm}
\end{aligned}
$$

and thus:

$$
[x]_{\text {om }}=\left[\begin{array}{cc}
1,22 & 0,11 \\
1,96 & -0,068
\end{array}\right]
$$

e) Corresponding horlzontal forces. We have:

$$
\{F\}=[\mathrm{K}]: x\}
$$

so that, 
First mode:

$$
\begin{aligned}
& F_{11}=9.720 \mathrm{~kg} \\
& F_{21}=15.120 \mathrm{~kg}
\end{aligned}
$$

Second mode:

$$
\begin{aligned}
& F_{12}=5.720 \mathrm{~kg} \\
& F_{28}=-3.540 \mathrm{~kg}
\end{aligned}
$$

therefore:

$$
[F]_{\mathbf{k B}}=\left[\begin{array}{rr}
9.720 & =15.720 \\
15.120 & -3.540
\end{array}\right]
$$

and therefore:

$$
F \text { total }=\left\{\begin{array}{l}
11.300 \\
15.200
\end{array}\right\}
$$

We plot the results in Fig. 18 together with those for $N 715$ floors in Fig. 19.

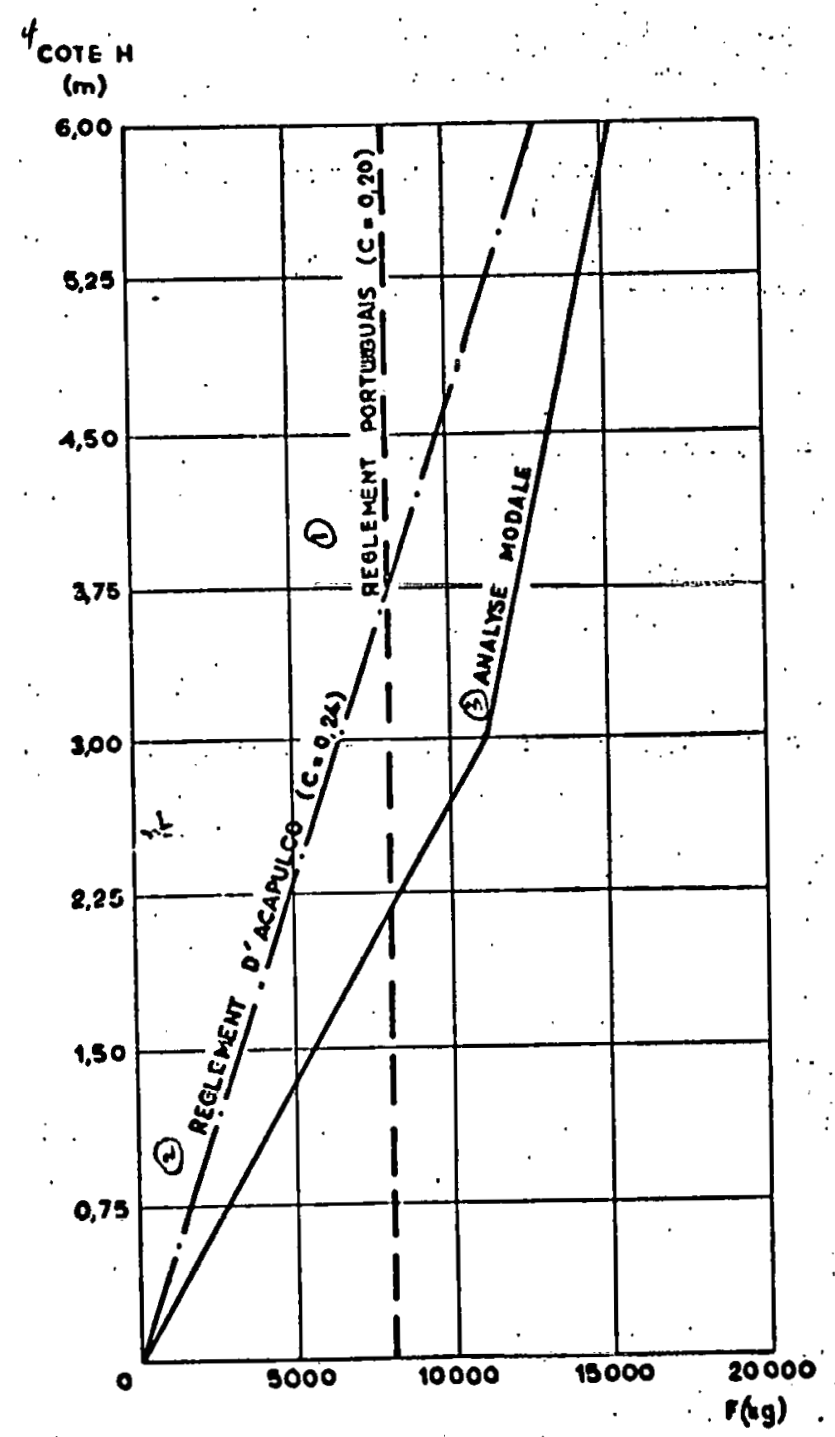

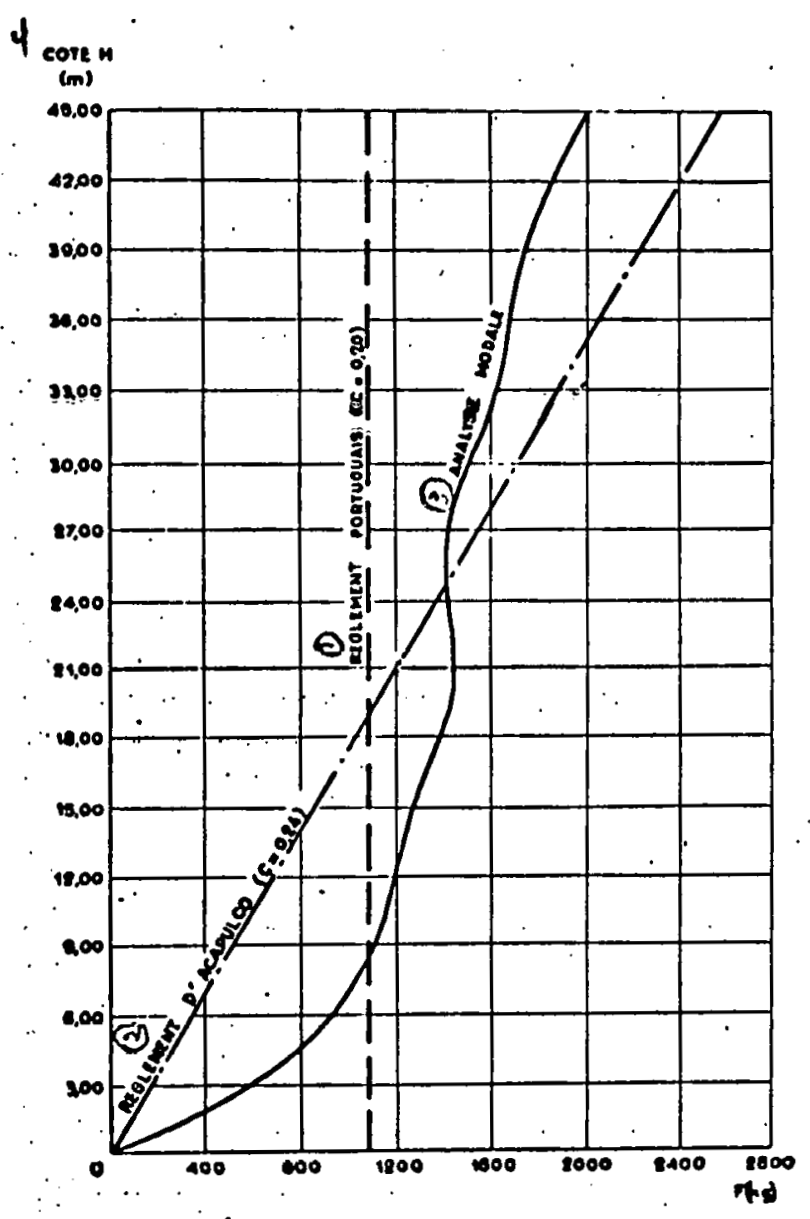

Fig. 19.

Fig. 18.
1) Portugal code.
2) Acapulco code.
3) Modal analysis
4) Level $\mathrm{H}$

Iig. 18. 
f) Varlations of forces with the parameters of the structure

QL_Variation_with the mass. For the type of structure invest1gated, the values of:

$$
\alpha=\frac{m}{k} \omega_{2}
$$

and of the vibration modes $[\phi]$ are independent of $\mathrm{m}$.

With regard to the amplitude of the equivalent oscillator given by :

$$
\boldsymbol{R}_{1}=\frac{\mathbf{R}_{4}}{\mathbf{M}_{8}} x_{\max }
$$

and the horizontal forces $F$ which are directly proportional to the amplitude, the law of varlation is:

$$
\frac{\dot{c}}{\mathbf{E}_{1}}=\frac{\mathbf{F}}{\bar{F}_{1}}=\sqrt[4]{\left(\frac{m}{m_{1}}\right)^{2}}
$$

It must be noted here that in antiearthquake codes, $F$ is directly proportional to $\mathrm{m}$.

B2_Variation with damping. On the basis of general equations, we easily verify that the law of variation between $F$ and $v$ is given by:

$$
\frac{\mathbf{F}}{\mathbf{F}_{1}}=\sqrt{\frac{\mathbf{v}_{2}}{v}}
$$

12_Variation with the rigidity. From the general equations, we easily deduce that:

$$
\frac{F}{F_{i}}-\sqrt[6]{\frac{k}{k_{i}}}
$$

an expression which shows that the forces are highly sensitive to variations in the rigidity of the structure.

(To be continued) 


\section{PART III \\ (Continuation and End) \\ METHODS OF CALCULATION \\ Chapter I--Calculation of Seismic Spectra}

In earthquake engineering, the term "seismic spectrum" is defined as the graphic representation of the variations of the relative displacement of the relative velocity (with respect to the ground) and of the absolute acceleration of a system of one degree of freedom as a function of the natural period of vibration $T$, with the base of this system being subjected to a stress of a seismic type.

The seismic spectrum can also be called the response spectrum, because the system with one degree of freedom responds (reacts) to the seismic shock.

To make the transition from a system of one degree of freedom to that of $n$ degrees of freedom, it suffices to apply the equivalence coefficlent to the seismic spectmum of the structure with one degree of freedom in order to obtain the spectrum of the structure with $n$ degrees of freedom.

We will investigaté the different methods utilized to obtain these spectra.

A. Determination of the Spectrum by Analytical Integration

The analytical determination of the velocity spectrum by direct Integration is by far the most precise.

We will express the selsmic stress by a series of damped harmonic functions $U_{0}^{\prime \prime}(t)$ representing the ground accelerations and we can determine these from a seismogram by separating it into a sertes of successive pulses.

Following the Russian professor, I. L. Korclnski, who has 
simplified the method proposed by H. P. Berlage in 1924 in France, we let:

$$
U_{0}^{\prime}(t)=-\sum_{1}^{n} a_{0} \varphi^{2} e^{-\infty \alpha} \sin (\varphi t+\gamma)
$$

where $a_{0}=$ initial displacement;

$\varphi=$ angular frequency of the seismic wave;

$\varepsilon_{0}=$ damping of the seismic wave;

$\gamma=$ angle defining the moment when component 1 becomes effective.

To utilize this expression for $U_{0}^{\prime \prime}(t)$, it is necessary to know the parameters which define it. Following a study of a large number of seismograms in the USSR, I. L. Korcinski arrived at the following conclusions :

The periods Tof seismic shocks which correspond to the maximum accelerations vary in the interval of $0.25-0.75 \mathrm{sec}$.

The mean value of the damping decrement $\delta_{0}$ is in the order of:

$$
\delta_{0}=\frac{2 \pi}{\varphi} \varepsilon_{0}=0,10
$$

Starting from these statistical results, we can assume that the selsmic shock can have the form (1) where the value $\frac{2 \pi}{\varphi} \varepsilon_{0}$ is constant for all terms of the series and where the value of $\varphi$ is arbitrary in an interval $\left[\varphi_{1}-\varphi_{2}\right]$.

However, the problem still remains very complicated because a very large number of undetermined terms remain in the expression for $\mathrm{U}_{0}^{\prime \prime}$.

We should therefore make another simplification. It is evident that the most important influence on a system with one degree of freedom will be produced by the component of series (1) whose frequency $2 \pi / \varphi$ will be nearest the fundamental frequency of oscillation of this system.

From the standpoint of practical calculation, we can therefore consider only the component of the series: 


$$
U_{0}^{\prime}(t)=-a_{0} \varphi^{2} \sigma^{-\sigma \alpha} \sin \phi t
$$

with

$$
\phi<\left[\phi_{1}-\phi_{2}\right]
$$

For a system with $n$ degrees of freedom subjected to the influence of an earthquake, the acceleration of which can be expressed by Eq. (2), Prof. I. L. Korcinski has formulated the expression giving the force of inertia which arises at point $K$ for the vibration mode 1 :

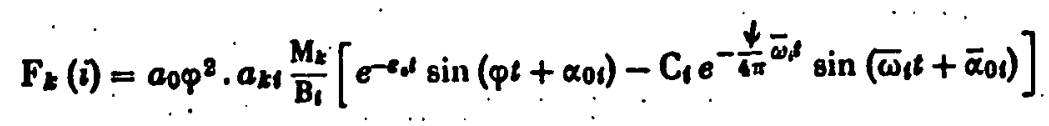

where $B_{1}, C_{1}, \alpha_{01}, \dot{\bar{\alpha}}_{01}$ are coefficients which depend on the characteristics of the structure and of the earthquake.

$$
\begin{aligned}
& \bar{\omega}_{r}=\sqrt{\omega_{l}^{2}-\varepsilon^{2}} \\
& \frac{\psi}{4 \pi}=\frac{c \phi}{\omega_{1}^{2}} \quad \text { form factor } \\
& a_{k t}=\text { coefficient de forme. }
\end{aligned}
$$

We note that $a_{0} \phi^{2}$ represents the maximum acceleration of the seismic shock; we let:

$$
K_{\mathbf{c}}=a_{0} \Phi^{\mathbf{2}}
$$

which we call the seismic coefficlent and which characterizes the degree of selsmicity of the region.

We let:

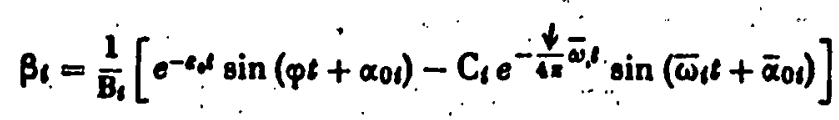

This factor varies as a function of time and depends on the ratio $c_{1}$ as well as the damping characteristics of the structure and of the earthquake $\varepsilon_{0}$; we: will call it the dynamic coefficient and it has the form of a spectral function.

We therefore have:

$$
F_{k}(i)=K_{2} a_{k 1} \beta_{1} M_{k}
$$


The total force at the base is:

$$
F_{k}=\sum_{i=1}^{n} F_{k}(i)=K_{1} \sum_{k=1}^{n} a_{k 1} \beta_{1} M_{k}
$$

The varlations of coefficient $\beta$ as a function of the natural frequency $T$ are given in Fig. 20 .

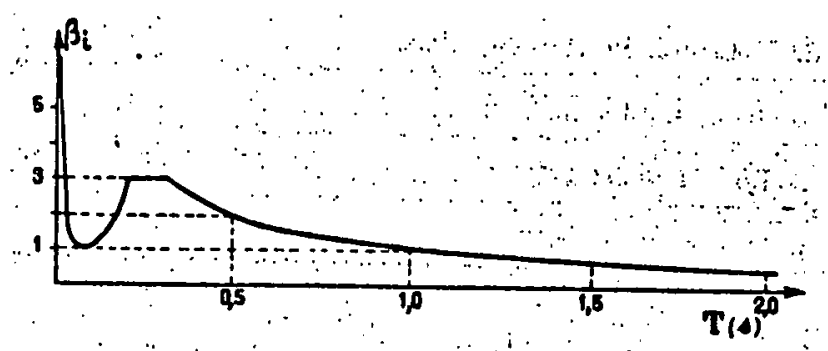

Fig. 20.

Housner coefficients relating the values of the maxima of velocity, displacement and acceleration by the oseillators subject to different earthquakes.

\begin{tabular}{|l|c|}
\hline Earthquake & Coemeient \\
\hline 1. El Centro, $5-18-1940 \ldots \ldots \ldots \ldots$ & 2,7 \\
\hline 2. El Centro, $12-30-1934 \ldots \ldots \ldots \ldots$ & 1,9 \\
\hline 3. Olympia, $4-13-1949 \ldots \ldots \ldots \ldots$ & 1,9 \\
\hline 4. Taft. $7-21-1.952 \ldots \ldots \ldots \ldots \ldots$ & 1,6 \\
\hline 5. Vernon, 3-10-1933.......... & 1,5 \\
\hline
\end{tabular}

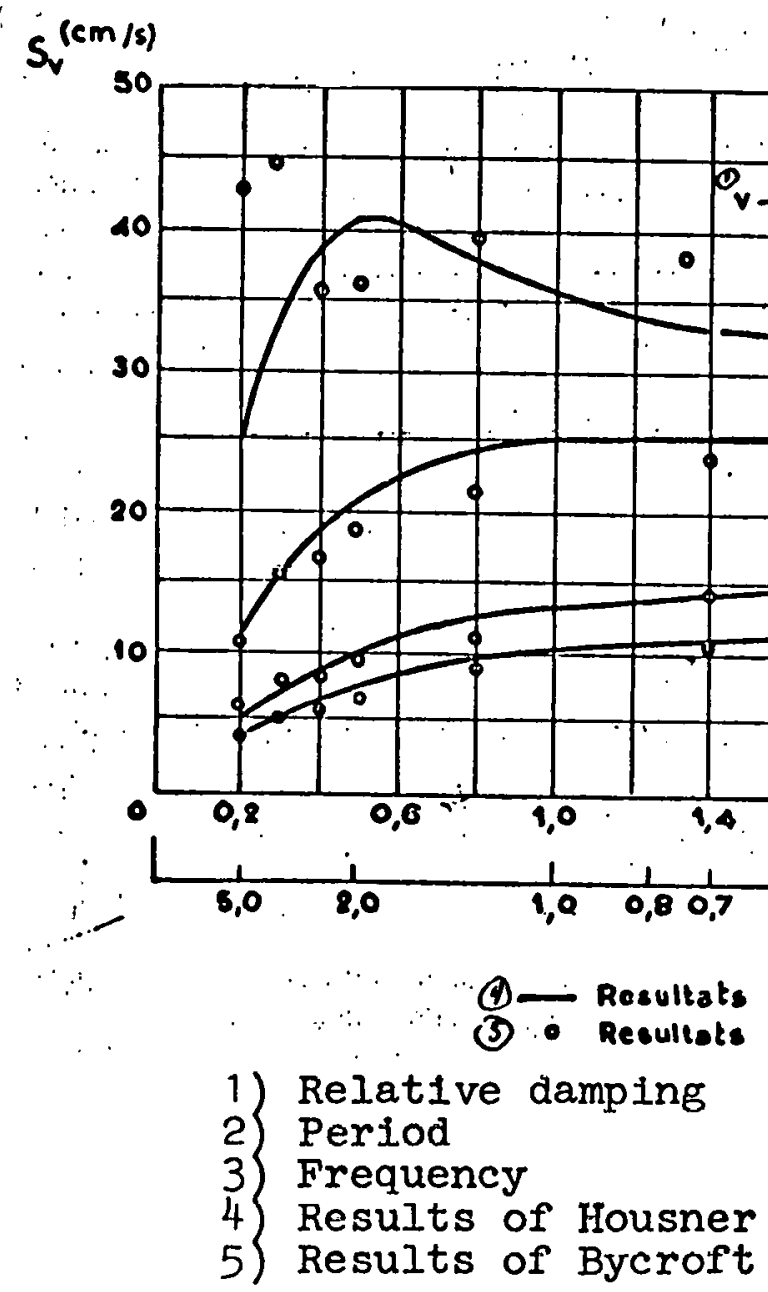

Fig. 21.--Mean velocity spectrum $S_{v}$ according to Housner and Bycroft. 
Chapter II--Practical Determination of Natural Frequencles of Vibration and of Damping

We can theoretically calculate the natural frequencies as a consequence of the results of the second part. But this requires a large number of computations which are difficult to perform without a computer.

We will therefore present approximate methods of calculation and especially, the experimental methods to determine the natural frequencies of a structure:

A. Approximate Calculating Methods

Direct expression of the frequency.---On the basis of theoretical studies, M. Ifrim formulated a fairly accurate expression which .. directly furnishes the natural frequencles of a high-rise structure as a function of its resistance. This formula is based on the principle of conservation of energy and the hypothesis that from the practical standpoint, the rigidity of the floors should be considered as infinite:

Fig. 23 (right) .--Variation of $\psi$ as a function of the number of floors $n$.

Fig: 22 (below).--structure with n floors.
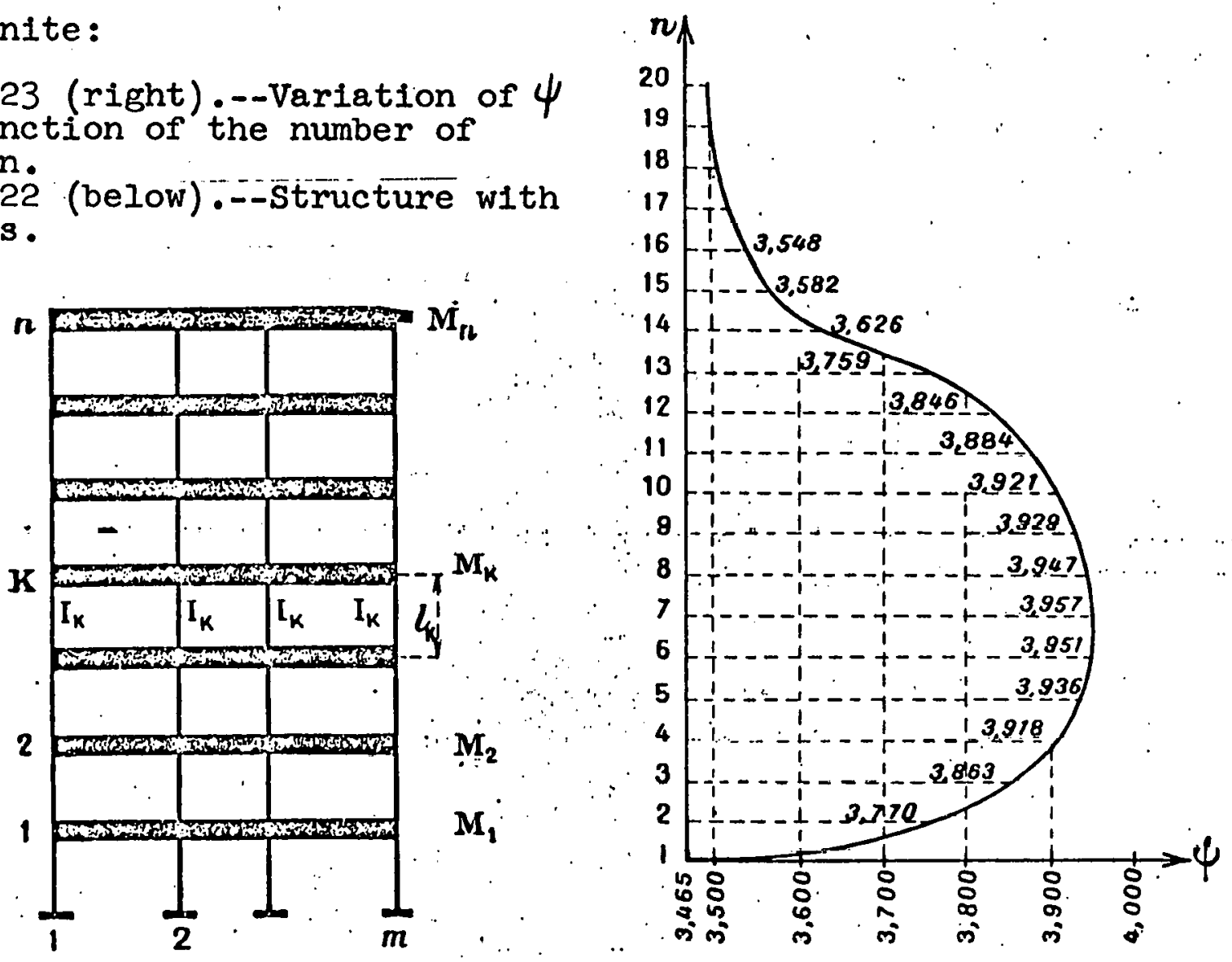
M. Ifrim established the formula:

$$
\omega_{1}=\xi_{1} \sqrt{\frac{E I_{0}}{M_{0} l_{0}^{j}}}
$$

where $I_{0}, I_{0}, M_{0}$ are arbitrary quantities and constants permitting a definition of the coefficients $\lambda_{k}, K_{k}, \alpha_{k}$ by the relations (Fig. 22):

$$
\begin{aligned}
l_{k}=\lambda_{k} l_{0} & \text { height between levels } K \text { and } K-1, \\
I_{k}=K_{k} I_{0} & \text { moment of inertia of studs between } \\
M_{k}=\alpha_{k} M_{0} & \text { levels } K \text { and } K-1, \\
& \text { mass at level } K .
\end{aligned}
$$

$n=$ number of floors,

$$
\xi_{1}=\psi \sqrt{\frac{m}{\alpha_{1} q_{1}+\alpha_{2}\left(q_{1}+q_{2}\right)+\ldots+\alpha_{n}\left(q_{1}+\ldots+q_{n}\right)}}
$$

$\psi=$ defined by the graph of Fig. 23,

$\mathrm{m}=$ the number of studs,

$$
-q_{k}=\frac{\lambda_{i}}{K_{k}}
$$

The value of the higher frequencies of vibration can be calculated approximately by the relation:

$$
\omega_{1}=1,3 i . \omega_{1} \text { with } 1=2,3,4 \ldots
$$

These formulas are applicable to the case where the structure changes shape with height by defining $\mathrm{K}_{k}$ by the formula:

with

$$
\mathrm{K}_{k}=\frac{1}{m} \cdot \sum_{1}^{m} \mathrm{~K}_{\mathrm{sk}}
$$

$$
K_{j k}=\frac{I_{f k}}{I_{0}}
$$

where $I_{j k}$ represents the moment of inertia of the stud located on row $f$ and column $k$.

This method leads to excellent precision because the frequencies are determined within $\pm 1 \%$ of the exact frequency given by the mathematical calculation. 


\section{B. Experimental Methods of Calculation}

At the time of my studies in Lisbon, tests were being conducted which included a study program with prefabricated structures which were compared to conventional buildings so as to determine their possibilities of earthquake resistance.

Three buildings of different type were constructed in real scale on the laboratory test stand (photograph of Fig. 24).

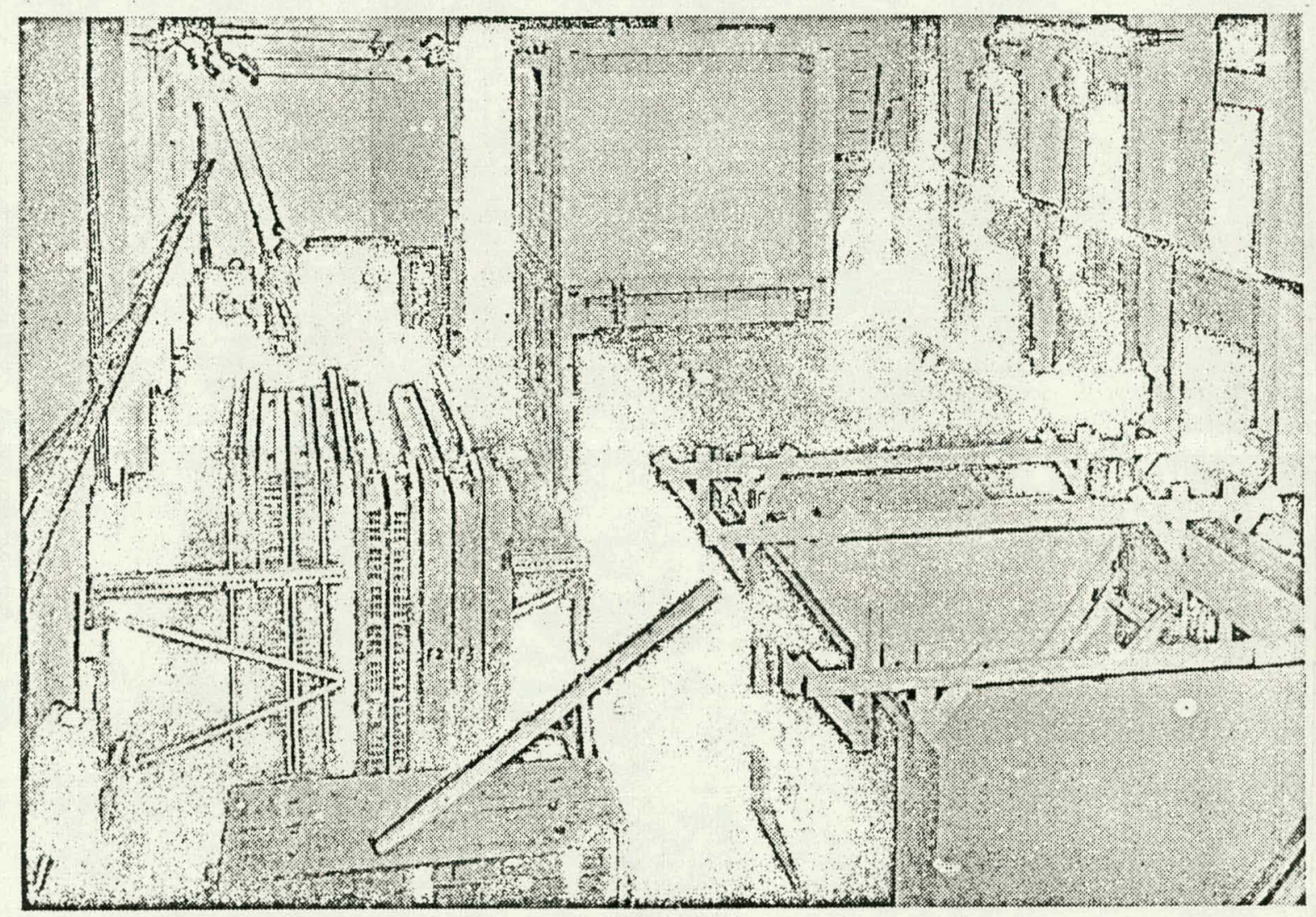

Fig. 24.

One conventional building with beams and studs and brick filling. One prefabricated building of the reinforced Fiorio type. One prefabricated building of the ordinary Fiorio type.

A sinusoidal vibrator generating a sinusoidal force in a fixed plane was mounted to the roof of each building and the displacements of the top of the structure were recorded while the vibration frequency was varied. 
We thus obtained a curve showing the resonance frequency of the building which corresponds to the maximum of the vibration amplitude and which was thus equal to the first vibration mode of the structure.

This method therefore permitted us to define also the damping factor, since the scále concept does not play a role here.

The natural frequencles of the three buildings were in the order of $13 \mathrm{~Hz}$, but since they were interconnected by the test stand on their base, an interference in the response curves of the three buildings existed.

For this reason, the response curve of two of the bulldings was studied while the third was subjected to the sinusoidal shock.

The investigators also fixed the second building at the level of the second floor, for example, which inhibited the resonance of this second building during tests made on the first and the third buildings.

C. Damping Factor

Damping is a very important factor in the anti-earthquake calculation and has a direct influence on the dynamic response of the structure and on the effects produced by the earthquake. From the analytical point of view, the effect of damping is expressed in the velocity spectrum which characterizes the intensity of the earthquake.

We start from the velocity spectrum:

$$
S_{v}=\int_{0}^{1} U_{0}^{*}(\tau) e^{-y, \omega_{i}(l-\tau)} \sin \omega_{i}(l-\tau) d \tau
$$

We can conclude that when the damping factor increases, the velocity spectrum will decrease and vice versa.

A structure having a high damping factor therefore has a significant capability for dissipation of energy and a favorable behavior when it is subject to an earthquake. 
The determination of the damping properties of a structure is a very difficult problem from the theoretical as well as the experimental standpoint because a large number of factors intervenes.

on the ba'sis of existing calculations and experiments, we can determine critical damping factors for different types of structures; in earthquake engineering, we assume the absolute damping factor $\varepsilon_{i}$ and the critical damping factor $\nu_{1}$ to be interrelated by:

$$
v_{t}=\frac{c}{\omega t}=\frac{8}{2 \pi}
$$

where $\delta$ is the logarithmic decrement of damping which is directly determined from the recorded data.

The critical damping factor $\downarrow$ is always smaller than unity.

From the practical standpoint, the problem consists of the experimental determination from recorded data of the critical damping factor $v$ which characterizes the different types of structures as a function of the materials.

It is evident that the damping of a given structure as a whole is a function of the type of structure as well as of its coupling with the ground. Moreover, the soll: of the foundation plays an important role in the overall damping in view of the very extensive deformations which it may undergo.

If we return to the damping of a structure, we can assume from the analytical standpoint that it is proportional to the velocity (Volgt hypothesis). This hypothesis is valid in the elastic region. In an oscillating system subjected to a forced vibration, damping causes a reduction in the response of the stmucture.

In existing structures, the nature of damping is not simple to define. To determine the critical damping factor in practice, we must consider all elements of the structure which absorb energy. Within this context, we can consider the following: 
The energy stored in the structure under the influence of the earthquake (kinetic energy);

The elastic energy of deformation;

The dissipated energy (absorbed in large deformations, cracks);

Energy lost by friction in the form of heat;

Restored energy, i.e. furnished by the structure to the ground (interaction phenomenon).

In the case of a maximum stress, an energy equilibrium exists (principle of conservation).

The kinetic energy furnished by the earthquake plus the restored energy should be equal to the energy of deformation plus the energy dissipated in the form of heat plus the energy lost in the cracks.

In the following table, the values given by different authors for the critical damping factor $\forall$ are listed. We can note that the majority of investigators are in agreement on considering $\nu=0.10$ for reinforced concrete structures.

J. A. Blume notes that the damping factor $\downarrow$ in the case of existing constructions has a value of between 0.05 and 0.10 .

Thus, as far as earthquake engineering is concerned, the value of $V^{\prime}=0.05$ should be accepted for all types of structures.

Critical damping factors

\begin{tabular}{|c|c|c|c|c|c|}
\hline \multirow[b]{2}{*}{$\begin{array}{l}\text { Type of } \\
\text { construction }\end{array}$} & \multicolumn{5}{|c|}{ Name of author } \\
\hline & J. A. Blume & L. S. Jacohson & $\begin{array}{l}\text { G.w. Hougner } \\
\text { R.C. Mtorrilt }\end{array}$ & S. C. Nepotvaridze & F. Y. M. Tsul \\
\hline Monolithic structure & - & : & - & - & - \\
\hline Massive construction & $\because$ & $0 ; 05-0,10$ & . - & - & - \\
\hline $\begin{array}{l}\text { Metalifc } \\
\text { construction }\end{array}$ & - & . - & - & 0,03 & $0,03-0,06$ \\
\hline $\begin{array}{l}\text { Reinforced concrete } \\
\text { construction }\end{array}$ & $0,05-0,10$ & $0,10-0,16$ & $0,07-0,10$ & 0,09 & $0,07-0,019$ \\
\hline $\begin{array}{l}\text { Masonry } \\
\text { construction }\end{array}$ & - & $0,10-0,18$ & - & 0,06 & 0.19 \\
\hline
\end{tabular}


Chapter III--Modern Methods of Calculation of Selsmic Forces: Paraseismic Criteria

Our present knowledge in earthquake engineering which we have attempted to describe does not permit a dynamic calculation proper, because the physical characteristics of structures, of the foundation terrain and the destructive power of selsmic waves are not sufficiently well known.

For the moment, the consideration of equivalent static loads evaluated on the basis of dynamic considerations represents the most advanced stage of the calculating methods and this is reflected in earthquake-resistance codes.

\section{A. Determination of Selsmic Forces}

The seismic forces are given by:

1.e.

$$
F_{k}(i)=M_{k} a_{k t} \omega_{i} \int_{0}^{t} U_{0}^{n}(\tau) e^{-\nu_{,} w_{1}(t-\tau)} \sin \omega_{t}(t-\tau) d \tau
$$

$$
F_{k}(i)=\left[\frac{2 \pi}{T_{t}} S_{v}\right] a_{k t} M_{k}
$$

If we let:

$$
C\left(T_{1}\right)=\left[\frac{2 \pi}{T_{1}} S_{v}\right]-\frac{\alpha}{T_{i}}=K_{l} \beta_{1}
$$

which is called the selsmic" spectrum coefficient in the case of a seismic mass.

We have:

$$
F_{k}(i)=C\left(T_{1}\right) a_{k t} M_{k}=K_{,} \beta_{1} a_{k t} M_{k}
$$

The first expression of $F_{k}(1)$ is utilized by the American code (S.E.A.O.C. 1959/1960)

The second expression of $\mathrm{F}_{\mathrm{K}}(1)$ is the calculating formula formIng the basis for the Soviet regulations.

If we use the displacement spectrum $S d=S_{v} / \omega_{1}$ ( $S d$ is equal to the Medvedev action spectrum $X)$, we have:

$$
F_{k}(i)=M_{k} \omega_{i}^{2} a_{k i} X
$$


The total force at the base of the structure can be calculated with the method of the reduced mass for a structure with $n$ degrees of freedom:

$$
F(i)=M_{r}(i) C T_{i}
$$

i.e.

$$
F(i)=\mu(i) C(T i)\left[\sum_{k} M_{k}\right]
$$

where $\mu$ is the equivalence coefficient.

This expression furnishes the general form of the total force at the base for the vibration mode $i$ when the selsmic spectrum $C$ (TI) corresponding to a system with one degree of freedom is utilized.

On the basis of this seismic spectrum $C(\mathrm{~T} 1)$, we obtain the reduced. seismic coefficient or the equivalent seismic coefficient correspondIng to a system with $n$ degrees of freedom:

$$
C\left(T_{i}\right)=\mu(i) C\left(T_{i}\right)
$$

This reduced spectrum is used in the Mexican and American codes. We thus have:

$$
F(i)=C\left(T_{i}\right)\left[\sum_{k} M_{k}\right]
$$

which is the formula of the California regulations.

Knowing the total force at the base, the distribution of selsmic forces in the levels of the construction is given by:

$$
F_{k}(i)=F(i) \frac{M_{k} Z_{k+1}}{\sum_{k=1}^{k} M_{k} Z_{k+1}}
$$

We therefore have:

$$
\begin{aligned}
& F_{k}(i)=\mu(i) C\left(T_{i}\right)\left[\sum_{k} M_{k}\right] \frac{M_{k} Z_{k 1}}{\sum_{k} M_{k} Z_{k t}}=\frac{\left|\sum M_{k} Z_{k t}\right|^{2}}{\left[\sum_{k} M_{k}\right]\left[\sum_{h} M_{k} Z_{i t}\right]} \times \\
& \times \omega_{t} . S_{v}\left[\sum_{k} M_{k}\right] \frac{M_{k} Z_{k t}}{\sum_{k} M_{k} Z_{k t}}=M_{k} \omega_{t} \frac{\sum_{k} M_{k} Z_{k 1}}{\sum_{k} M_{k} Z_{i t}} Z_{k t} S_{v}
\end{aligned}
$$


which is the formula given at the start of this chapter.

$\frac{\text { B. Anti-Seismic Criterion in the Case of }}{\text { Reinforced Concrete Constructions }}$

The paraseismic criterion is defined by the comparison of the displacements which can be expected during earthquakes to permissible values. Additional conditions

\section{$8(\mathrm{~cm})$}

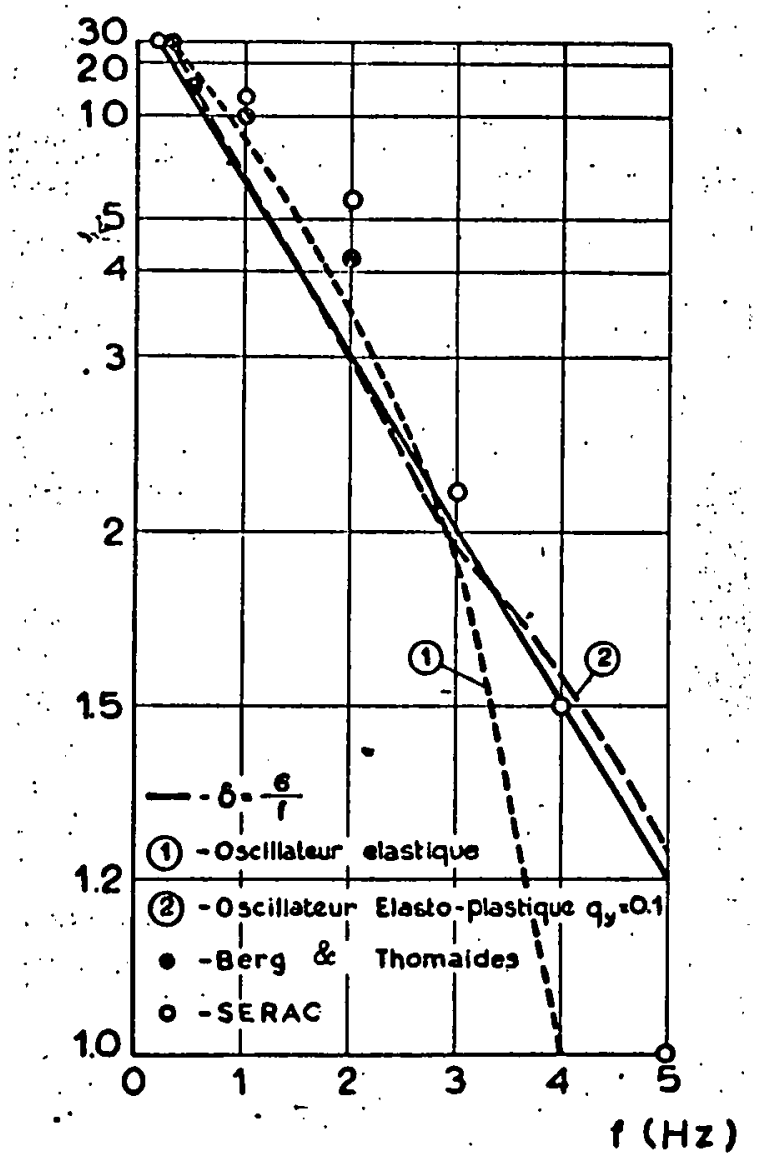

1) Elastic oscillator

2) Elastoplastic osc1llator Fig. 25

should also be taken into consideration so as to limit the deformations and guarantee a safety factor which is sufficient with respect to fallure. This study was performed at the L.N.E.C. by Mr. J. Ferry Borges.

It is important to correlate the maximum relative displacements of an oscillator with one degree of freedom to its natural frequency. The theoretical and experimental results shown in the graph of Fig. 25 show that we can write the following relation with sufficient precision:

$$
8 .=\frac{6}{f}
$$

where $\delta_{S}$ is the mean of maximum displacements and $f$ is the natural frequency of the oscillator.

This formula is valid only in the case of an earthquake with the spectral density $S_{0}=675 \mathrm{~cm}^{2} \mathrm{~s}^{-4} \mathrm{H}_{3}^{-1}$ (EI Centro N-S 1940); for another spectral density $s_{1}, \delta_{0}$ should be replaced by:

$$
8_{, 1}=\delta_{0} \sqrt{\frac{5}{5_{0}}}
$$


1. Maximum displacement due to the earthquake.--The behavior of a reinforced concrete structure (at a given level) can be compared to that of an oscillator with one degree of freedom, the mass of which is that of the levels above this level and whose rigidity is that of the reinforced concrete studs (Fig. 26):

If all studs are identical with the

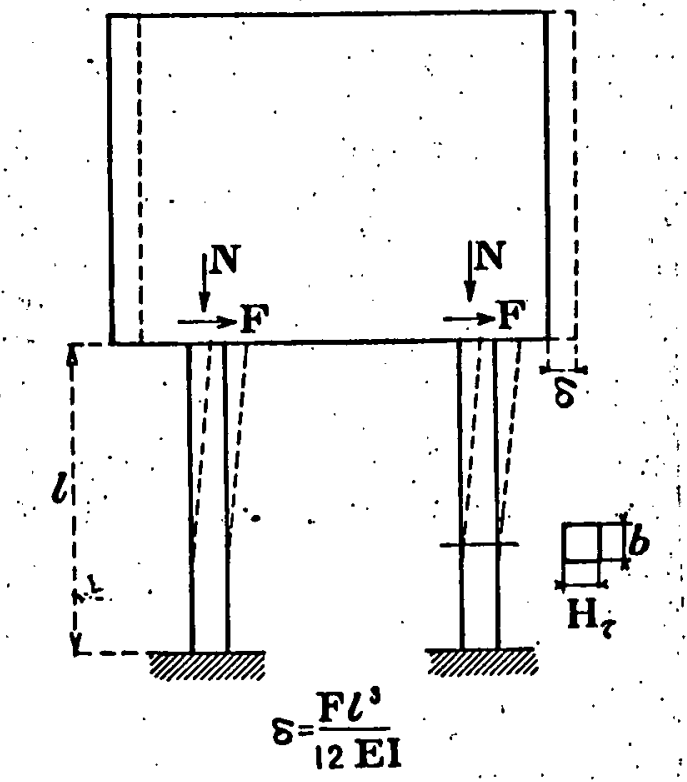

Fig. 26. same axial load $\mathrm{N}$ and perfectly confined in the floors, the natural frequency of the system is given by:

$$
f=\frac{\sqrt{8}}{2 \pi} \sqrt{\frac{12 \mathrm{EI}}{\boldsymbol{N}^{\mathfrak{l}}}}
$$

where $I$ is the moment of inertia of the studs.

Since the studs are rectangular, we let:

$$
\begin{aligned}
& \begin{array}{l}
H=1,1 \mathrm{H} \\
\mathbf{E}=21.000 \sqrt{\sigma_{\text {ow }}}
\end{array} . \mathrm{H}=\text { useful height }_{\text {in } \mathrm{kg} / \mathrm{cm}^{2}} \\
& B=9,8 \mathrm{~m} / \mathrm{s} 2 \text {. } \\
& \sigma_{0}=\frac{N}{b h}
\end{aligned}
$$

we have:

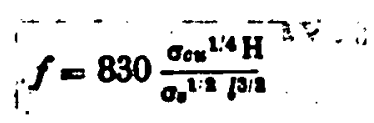

The frequency thus calculated corresponds to the behavior before cracking, for cracking reduces the elastic rigidity. This reduction depends on numerous factors: percentage of steel, as well as the moments which act on the studs. On the basis of simple hypotheses, it is possible to obtain an order of magnitude of this reduction and to show that in the usual cases, it will correspond to multiplying the elastic rigidity of the total cross-section of reinforced concrete by a coefficient varying between 0.4 and 0.6 . The natural frequency is then reduced by about 0.63 to 0.77 of the preceding value. 
Recent tests with reinforced concrete columns have confirmed these reduction factors.

We therefore have:

$$
f=600 \frac{\sigma_{a u^{1 / 4}} H}{\sigma e^{1 / 9} g^{3 / 2}}
$$

According to Expression (1), the maximum displacement due to the earthquake under consideration is:

$$
\delta_{c}=0,01 \frac{\sigma_{0}^{12 p a r}}{\sigma o w_{0 w^{1+H}}}
$$

2. Iimiting deformation of columns.--For an elastic rectangular countersunk beam, it is easy to show that the relative horizontal displacement of the two ends as a function of the difference of the deformations of the end fibers $\varepsilon=\varepsilon^{1}-\varepsilon^{2}$ is given by the relation:

$$
\delta^{*}=\frac{n}{4} \frac{n}{6}
$$
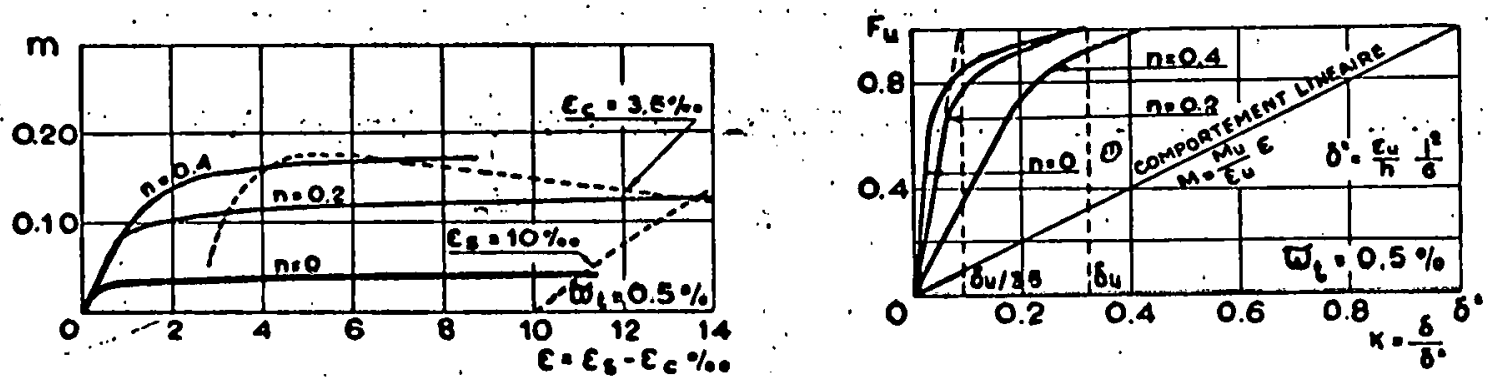

1) Iinear behavior
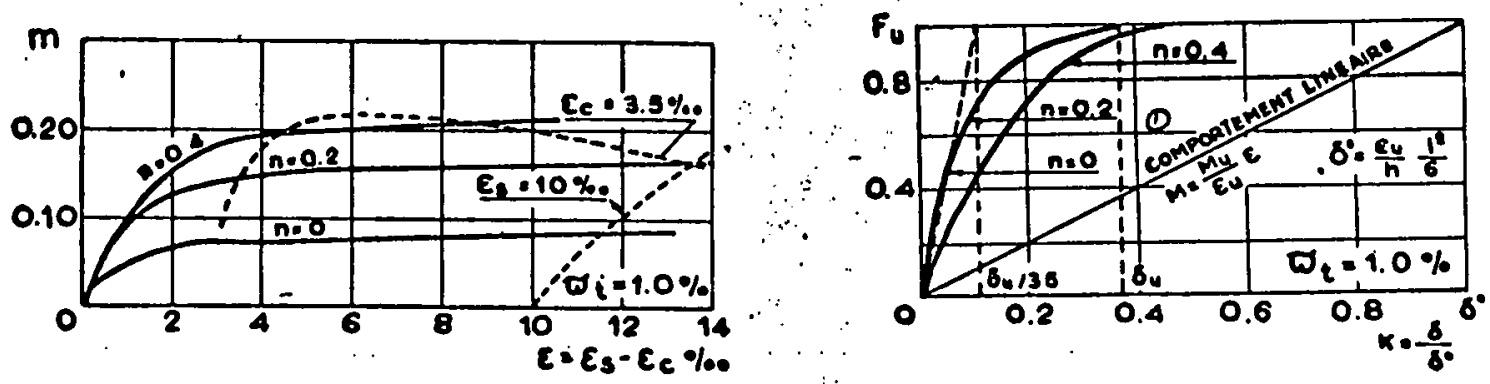

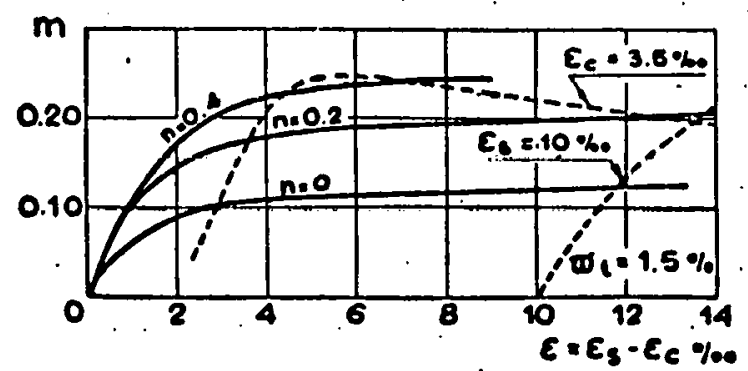

Fig. 27

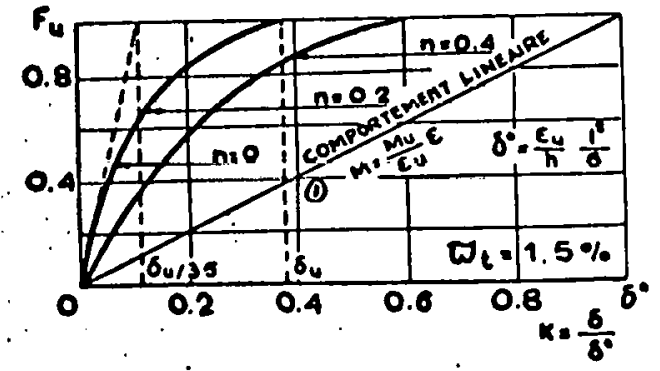

Fig. 28. 
If the behavior is not elastic, a correction factor $K$ must be Introduced; it depends on the nonlinear diagram which relates the bending moments $M$ to the difference of the end deformations. This difference can be considered as a reduced deformation and the correction factor therefore is a function of the moment-deflection diagram.

FIg. 27 shows the reduced moment-deflection diagrams for rectangular cross-sections symmetrically reinforced with steel 40 (conventional limit at $0.2 \%=40 \mathrm{~kg} / \mathrm{mm}^{2}$ ) with a concrete of $\sigma_{\mathrm{cu}}=300 \mathrm{~kg} / \mathrm{cm}^{2}$. The total percentage of steel varies between 0.5 and $1.5 \%$. Analogous diagrams can be obtalned for other grades of steel and concrete.

By integrating these diagrams, we easily obtain the relations indicated in Fig. 28 between the horizontal force $F$ and the displacement $\delta$. In these diagrams, we show those which correspand to the Iinear behavior that give us the same end deflection.

As shown. by Fig. 28, in the usual case, the factor $\mathrm{K}$ can be approximately taken at 0.4 and the maximum possible displacement of the beam in the nonlinear range can be expressed by the following as a function of the limiting difference between the end deformations $\varepsilon_{u}$ :

$$
8_{u}=0,067 \frac{l^{a}}{c_{u}}
$$

Since the deformations of the concrete should not exceed $3.5 \%$, a relation can be obtained between $\varepsilon_{u}$ and $n$ (n designates the reduced compressional load $n=\frac{N}{\mathrm{bH}_{\sigma_{c u}}}$ ).

This relation is nearly independent of the quality and the percentage of steel and for the values of interest can be expressed in sufficient approximation by:

$$
e_{u}=\frac{3.10^{-1}}{n}
$$

If we replace $\varepsilon_{u}$ by its value in the expression of $\delta_{u}$, we obtain:

$$
\delta_{x}=2 \cdot 10^{-4} \cdot \frac{\sigma_{\text {osun }} \mathrm{n}}{\sigma_{0} \mathrm{H}}
$$


3. Comparison between seismic and permissible displacements.-Since the displacement due to earthquakes should be smaller than the permissible displacement according to our criterion, Expression should be smaller than Expression (4):

1.e.: $8, \leqslant 8_{u}$

i.e.:

$$
\begin{aligned}
& 0,01 \frac{\sigma_{0}^{211 \beta A}}{\sigma_{0 x} 1 / 4 H} \leqslant 2.10^{-4} \frac{\sigma_{\cos } H}{\sigma_{0} H} \\
& \sigma_{e}{ }^{3 / 2} \leqslant 0,12 \sigma_{c \omega} b^{3 / 4} l^{1 / 2}
\end{aligned}
$$

The maximum values of $\sigma_{c}$ are given by the graph in Fig. 29.

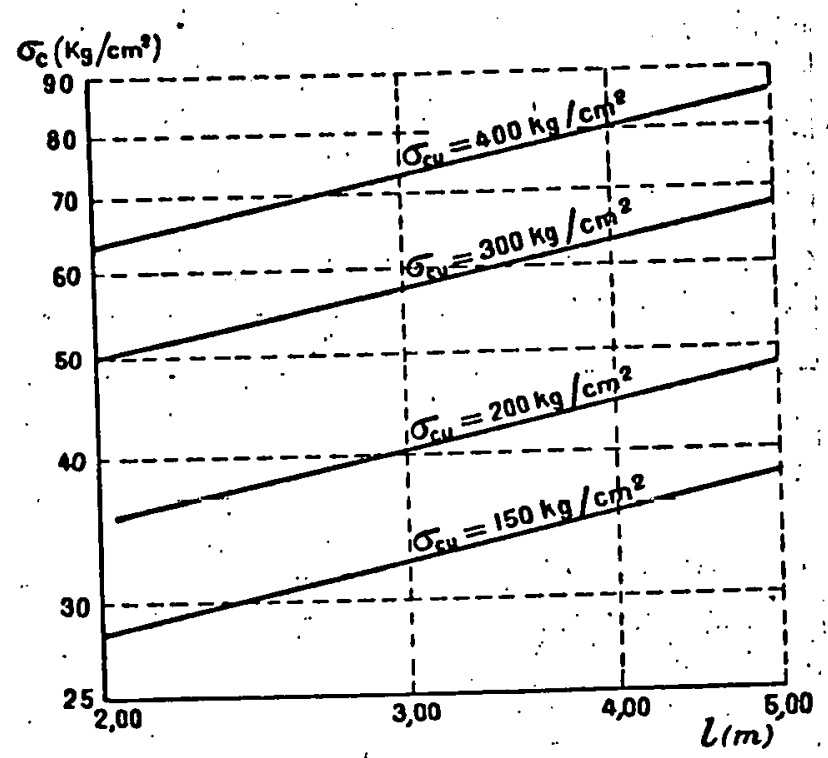

Fig. 39.

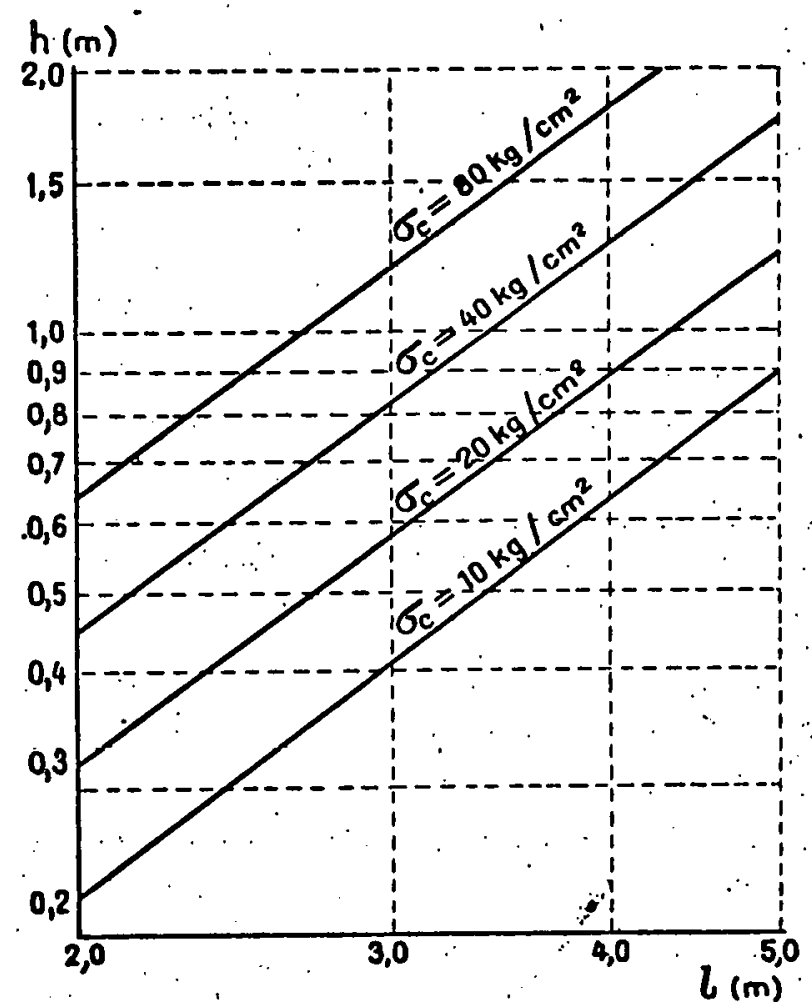

Fin. '30.'

For the usual qualities of concrete $\sigma_{\mathrm{cu}}=200-300 \mathrm{~kg} / \mathrm{cm}^{2}$ and beam lengths of $1=3-4 \mathrm{~m}, \sigma<0.19-0.226 \mathrm{~cm}$. This condition amounts to setting a limit to the mean reduced compression:

$$
n=\frac{\sigma_{0}}{\sigma_{0+0}}
$$


4. Limitation of displacements between floor levels.--Condition (5) assures that the permissible limiting strain will not be exceeded, but it does not limit the relative displacements between floor levels. To prevent the formation of excessive cracks and the rupture of partitions, we must take such a limit into consideration.

Expression (3) permits us to define the minimum value of $\mathrm{H}$ as a function of the amplitude $\delta$ under consideration:

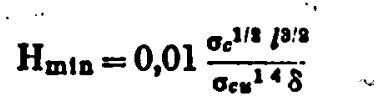

With consideration of the small influence of the quality of the concrete, we can let $\sigma_{\mathrm{cu}}^{1 / 4}=4$ and the above expression becomes:

$$
H_{\min }=25 \cdot 10^{-4} \sigma_{e}{ }^{1 / 2} l_{1}^{3: 2} \frac{l}{8}
$$

This expression is shown in the diagram of Fig. 30 for the value of $\delta=1 \mathrm{~cm}$. For other values of $\delta$, we only need to divide the limit height $H$ obtained on the graph by $\delta$.

This expression of $\mathrm{H}_{\min }$ can be easily extended to the case when the beams have different cross-sections. We let $I_{k}$ be the moment of inertia of the beam $K$ and $n$ the number of beams; the equivalent inertia of these beams should have the value of the inertia corresponding to $H_{\min }$ of Expression (7), 1.e.:

$$
\sum_{n=1}^{n} I_{k=n} \frac{b \mathrm{H}^{\mathrm{m}}}{12}
$$

Since the average compressive stresses may not vary much from one beam to the next, we have:

$$
\mathrm{A}_{t}=\sum_{k=1}^{n} b_{k} \mathrm{H}_{k}=n b \mathrm{H}
$$

and thus

$$
\sum_{k=1}^{n} \frac{I_{k}}{A_{1}}=\frac{H^{2} \min }{12}
$$

This condition provides for $a$ lower limit of the sum of moments of inertia of the beams at one level in any direction. 
5. Safety with respect to fallure.--The relations which we have formulated $f 1 x$ limits for the reduced normal stresses and the beam dimensions, but we have not yet considered the percentage of steel. When the limiting deformation of the beams was investigated (Par. 2), we demonstrated that the limiting value of permissible deflection was practically independent of the percentage of steel but depended primarily on the average compressive stress. This is correct only if a minimum percentage of steel exists. In fact, if there is no steel, the limit displacement corresponding to the steel could not be taken into account and the susceptibility to rotation would have to be reduced a great deal; the expressions above would thus no longer be valld.

An analysis of Fig. 28 shows that the ratio between the limiting displacement $\delta_{u}$ and the displacement corresponding to elastic behavior is very close to 3.5 for the values of the reduced compressive stress $n$ in the interval of $0-0.2$ of interest to us and for the normal percentages of steel.

Since this ratio should not exceed the value of 3.5 , the structure must resist a horizontal force equal to at least $10 / 35$ of the force which would be calculated in the case of elastic behavior.

For elastic behavior, the seismic coefficient can be calculated easily as a function of the natural frequency of the structure.

In fact, the elastic rigidity is:

$$
\frac{F}{8}-12 \frac{E I}{p} ;
$$

and in view of the preceding expressions:

we obtain:

$$
8,=\frac{6}{f} \text { and } f=\frac{\sqrt{g}}{2 \pi} \sqrt{\frac{12 \mathrm{EI}}{\mathrm{N}^{3}}}
$$

$$
C e=0,245 f
$$


Since the plastic. moment must be 3.5 times smaller than the elastic moment because of the non-linear behavior, we obtain:

$$
C=0,07 \mathrm{f}
$$

The reduced plastic moment should thus be:

$$
m=\frac{\mathrm{CN} l}{2 b \mathrm{H}^{\mathrm{a}}} \sigma_{\mathrm{cu}}=0,035 \frac{\sigma_{0}}{\sigma_{\mathrm{ovt}}} \frac{l}{\mathrm{H}} \dot{j}
$$

which, in view of Expression (2), is written as:

$$
m=\frac{21}{b^{1 / 2}} \frac{\sigma_{0} e^{2 / 2}}{\sigma o s^{2 \cdot 2}}
$$

We thus see that the reduced plastic moment is only a function of the mean compression of the concrete, the length of the beams and the quality of the concrete. Since the percentage of steel is therefore only a function of the reduced moment and the normal stress, this percentage does not depend on the shape of the beams.

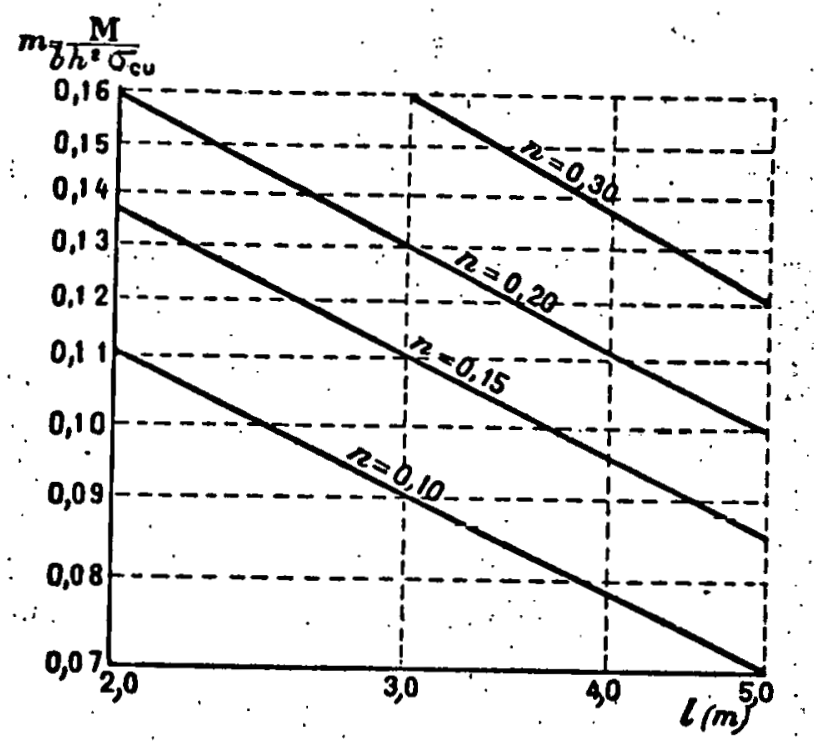

Fiz. 31. If we use $n=\sigma_{c} / \sigma_{c u}$ and $\sigma_{c u} \simeq 4$ as above, we have:

$$
m \rightarrow 5 \frac{n^{1 / 8}}{l}
$$

$m$ is shown graphically in Fig. 31 . The usual tables showing the percentage of steel as a function of $n$ and $m$ can be used to calculate the percentage of necessary steel.

For values of $\mathrm{n}$ between 0.19 and 0.22 , and the usual lengths of beams $(3<1<4 \mathrm{~m})$, $\mathrm{m}$ varles between 0.11 and 0.14 . Thus, for example, if steel of grade 40 is utilized, the percentage of steel for the reinforced concrete beams should be: 
If $\sigma_{c u}$ is equal to 200 or $300 \mathrm{~kg} / \mathrm{cm}^{2}$, the percentage of steel is 0.4 and $0.6 \%$ respectively, which is low.

6. Selsmic coefficient C.--The seismic coefficient C (8) is only a function of the natural frequency of the system and is 3.5 times smaller than that which corresponds to linear behavior (see the graph in Fig. 32).

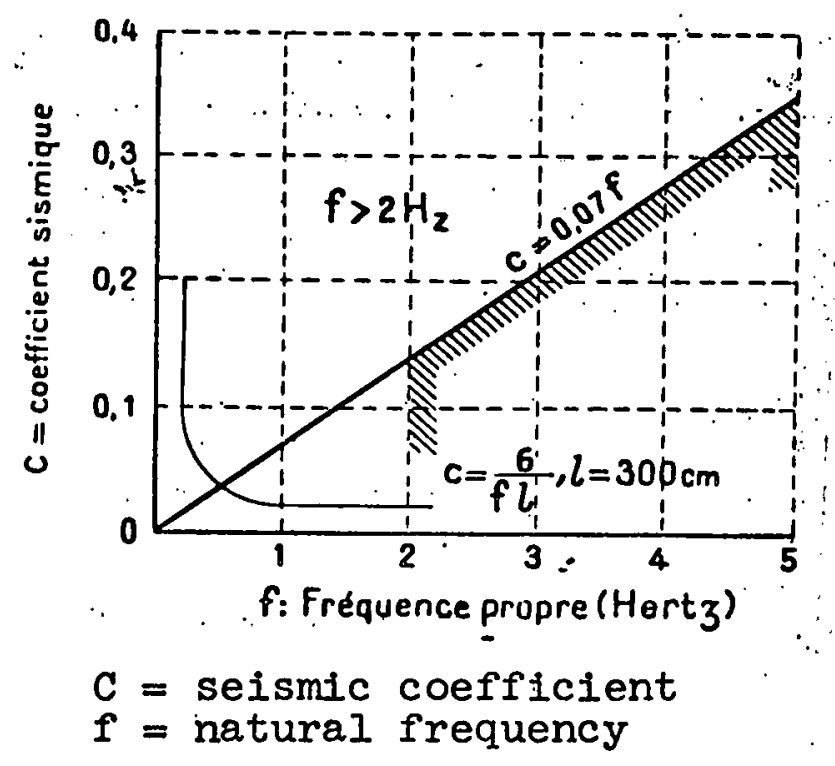

Fig. 32

This diagram shows that in the case of structures with a very low frequency, very small seismic coefficients can be adopted, but we must keep in mind that the limitation of relative displacements establishes a limit to the minimum natural frequency; thus for $I=3 \mathrm{~m}$ and $\delta<3 \mathrm{~cm}$, Expression (1) furnishes $f>2 \mathrm{~Hz}$ and thus according to (8), $c<0.14$.

If we neglect the deformation condition, a new condition $\left(c=\frac{6}{f I}\right)$ must be considered to prevent the moments due to the relative displacements of the structure from exceeding those which can be resisted by the beams.

In practice this shows that if the earthquake of El Centro of 1940 is used as reference, the seismic coefficient under consideration should vary between 0.15 and 0.25 according to the natural frequency of the structure.

The relations (5), (6) and (9) permit a direct determination of the permissible maxima of the reduced compressive stresses, the minimum beam height and the minimum percentage of steel for constructions of the investigated type. 


\section{PART IV}

\section{ELASTIC-PLASTIC BEHAVIOR OF STRUCTURES}

\section{Chapter I--Study of the Elastic-Plastic Behavior of Structures}

Up to this point, we have only studied pure elastic systems. But the deformations due to earthquakes are such that the elastic limit of the materials is exceeded. We therefore should study the dynamic behavior of elastic-plastic (or non-iinear) structures.

The non-linear behavior of a structure can be characterized by two important phenomeno from the qualitative standpoint:

A saturation phenomenon;

The equivocal nature of cause-effect relations (hysteresis).

The first phenomenon is expressed by a limit in the strength of materials constituting the structure, $1 . e$. It is impossible to exceed a certain value of the potential energy without changing the properties of the materials.

The second phenomenon reveals the existence of a transformation of mechanical energy into heat due to the existence of internal friction.

We can say that.in general, the first of these two effects is the most important. Actually, it can be verified experimentally that the hysteresis phenomenon does not differ from the phenomenon of viscous damping.

Studies generally are carried out with the following hypotheses: The principal characteristic of non-1inearity is expressed by the saturation phenomenon;

The phenomenon of hysteresis is treated as a viscous dampIng which furnishes an equivocal relation between cause and effect.

The principal advantage of these hypotheses is to permit an analytical study of the problem and thus to have information on the permanent deformations of the structure. 
Fig. 33 shows the most important parameters on the basis of which the oscillation with one degree of freedom will be studied.

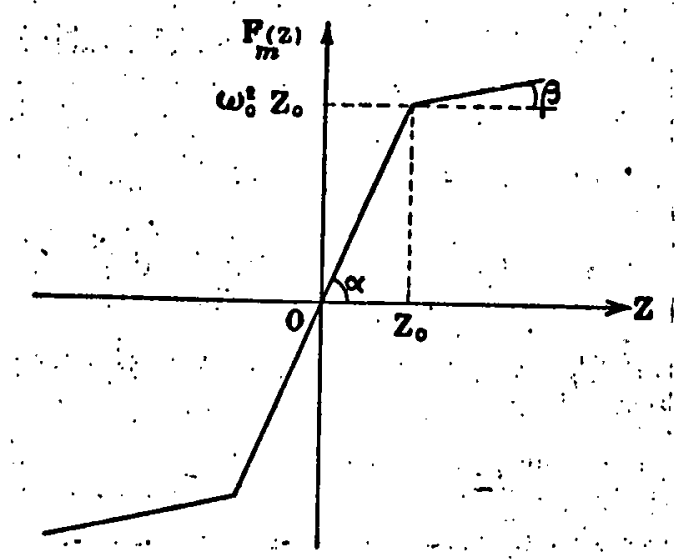

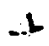

Fig. 33.

These characteristics will be defined by 3 parameters:

$$
\operatorname{tg} \alpha=\omega_{0}^{2} ; \operatorname{tg} \beta=8 \quad ; \quad G=\frac{\omega_{j}^{2} s_{0}}{8}
$$

The particular case of elasticplastic behavior exists when:

$$
\operatorname{tg} \beta=0
$$

The mathematical procedure which will be used to solve this problem is rather difficult.

The use of statistical methods of the Markov type, which are possible because of the equivocal characteristics, results in the solution in the form of an equation with partial derivatives called the Fokker-Planck equation.

Aside from a few specific cases, we will only study the stationary relation which fully justifies the high values of the equivalent viscous damping which we will determine.

\section{Calculation of the equivalent viscous damping.--We will}

determine the value of viscous damping which causes an energy dissipation equivalent to that due to the hysteresis phenomenon.

For a Iinear oscillator subjected to an excitation $a(t)$, we have:

$$
m \frac{d z}{d l^{2}}+2 n \omega_{0} m \frac{d z}{d !}+m \omega_{0}^{2} Z=-m \cdot a_{0}(l)
$$

By multiplying this expression by $d z / d t$ and integrating over a cycle, we have:

$$
\oint \frac{d}{d t}\left[m \frac{Z^{\prime}}{2}+m \omega_{0}^{2} \frac{Z^{2}}{2}\right] d t+\oint m a_{0} \frac{d z}{d t} d t=-\oint 2 m n \omega_{0}\left(\frac{d z}{d t}\right)^{\prime} d t
$$

The mean value of the first integral is zero, so that we have:

$$
\oint m a_{0} \frac{d x}{d t} d t=-\oint 2 m n \omega_{0}\left(\frac{d t}{d t}\right)^{2} d t
$$


This equality means that on the average the losses of a cycle are given by:

$$
\bar{\tau}=-\oint 2 m n \omega_{0}\left(\frac{d z}{d t}\right)^{2} d t
$$

For the characteristics of the bilinear oscillator represented on the graph in Fig. 34, we have:

$$
m Z^{*}+m \varphi\left(z, z^{\prime}\right)=-m a(t)
$$

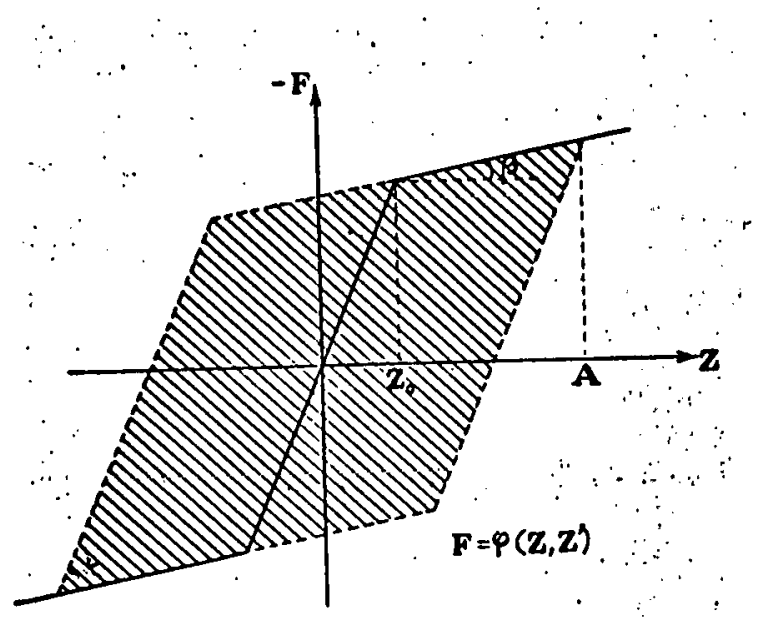

Fig. 31. .

We thus have:

$$
\bar{\tau}_{\mathrm{T}}=-\oint m \varphi(z, z) \frac{d z}{d t} d t
$$

which is nothing else than the shaded area in the graph.

We therefore have:

$$
\begin{array}{rlr}
\tau_{T}=-4 m \omega_{0}^{2} Z_{0}\left(A-Z_{0}\right) \gamma . & \text { if } A>Z_{0} \\
\tau_{T}-0 \quad \text { if } A \leqslant Z_{0}
\end{array}
$$

If we designate that $\gamma$ is

$$
\gamma=\cos \beta\left[1-\frac{\operatorname{gg} \omega}{\omega t}\right]
$$

We therefore have:

$$
\begin{aligned}
& \oint 2 m n \omega_{0}^{2}\left(\frac{d z}{d t}\right)^{\bullet} d t=4 m \omega_{0}^{2} Z_{0}\left(A-Z_{0}\right) \gamma \\
& \text { if } A>Z_{0} \\
& \oint 2 m n \omega_{0}^{2}\left(\frac{d z}{d t}\right)^{2} d t=0 \\
& \text { if } A \leqslant Z_{0}
\end{aligned}
$$

If the oscillator is elastic-plastic $\beta=0$, then $\gamma=1$ and:

$$
\begin{array}{ll}
n_{\text {eq }}=\frac{2}{\pi} \frac{\Lambda}{\bar{Z}_{0}}-1 & \text { if } A / Z_{0}>1 \\
\left(\frac{A}{Z_{0}}\right)^{8} & \text { if } A / Z_{0} \leqslant 1
\end{array}
$$

The graph of Flg. 35 represents the varlations of $\bar{n}_{\text {eq }}$ and of:

$$
\overline{\bar{n}}_{\text {eq }}=\frac{1}{\frac{\lambda}{z_{0}}} \int_{0}^{\frac{\Lambda}{z_{1}} n_{\text {eq }} d\left(\frac{\Lambda}{z_{0}}\right)}
$$




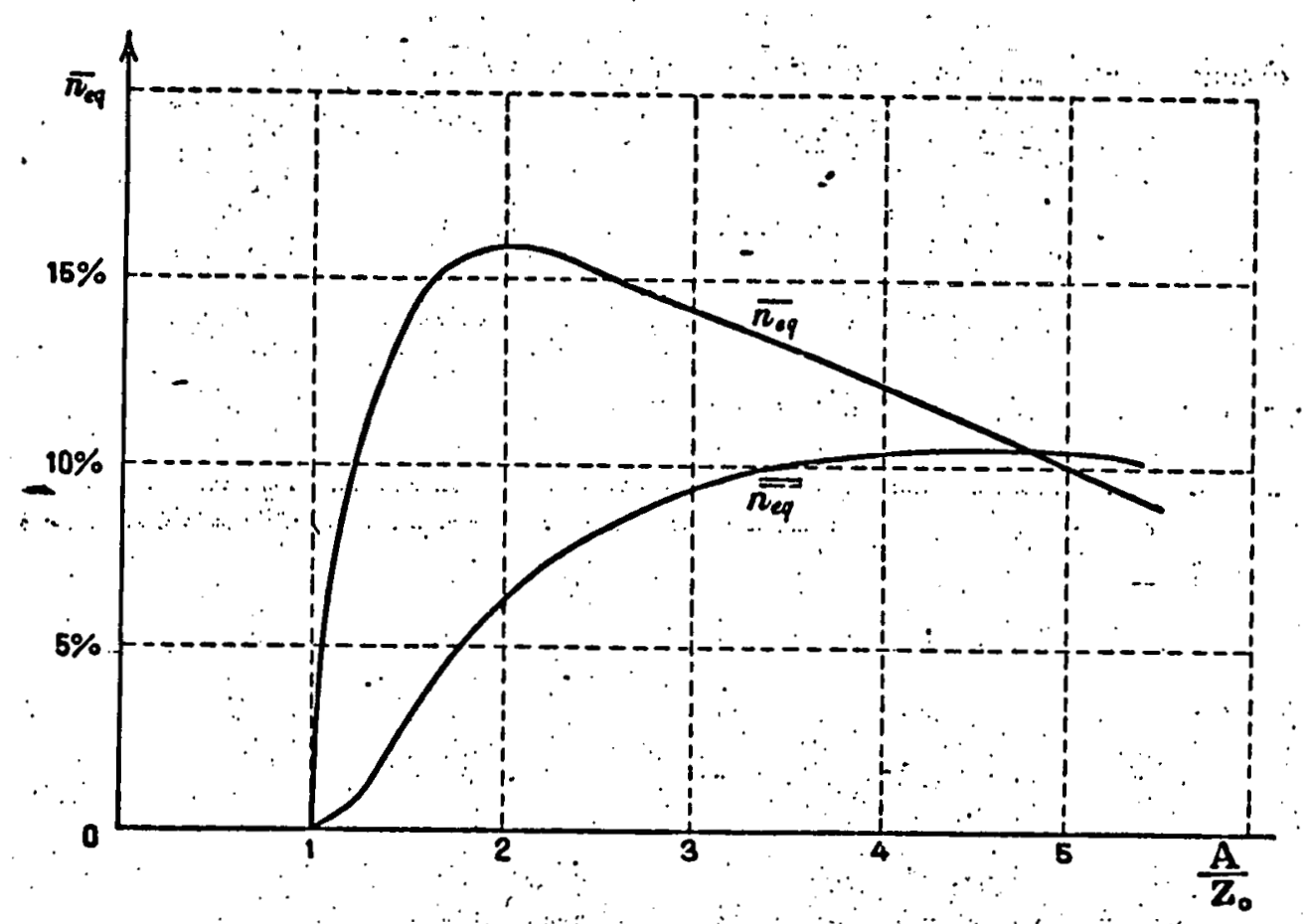

ris. 95

2. Integration of the Fokker-Planck equation.--Three distinct domalns exist for the variable $z, i . e .:$

$$
\begin{aligned}
\mathbf{Z} & <-\frac{1}{\mathbf{Z}_{0}} \\
-\mathbf{Z}_{0}<\mathbf{Z} & <\mathbf{Z}_{0} \\
\mathbf{Z} & <\mathbf{Z}_{0} .
\end{aligned}
$$

where $Z_{0}$ is the IImit elastic displacement.

For each of these domains, the equation of motion is:

$$
\begin{array}{ll}
\cdot \frac{d z}{d t^{2}}+2 n \omega_{0} \frac{d x}{d t}+\omega_{0}^{2} Z=-a(t) & -Z_{0}<Z<Z_{0} . \\
\cdot \frac{d z}{d d^{3}}+2 n \omega_{0} \frac{d z}{d t}+\left(\omega_{0}^{2}-\delta\right) Z_{0}+\delta Z=-a(t) & Z>Z_{0} . \\
\cdot \frac{d Z^{2}}{d t^{2}}+2 n \omega_{0} \frac{d z}{d t}-\left(\omega_{0}^{2}-\delta\right) Z_{0}+\delta Z=-a(t) & Z<-Z_{0}
\end{array}
$$

To make these equations dimensionless, we let:

$$
\begin{aligned}
& \theta=\omega_{0} t \\
& x=\frac{z}{z_{0}} \\
& r=\frac{8}{\omega_{3}^{2}} .
\end{aligned}
$$

and they become: 


$$
\begin{aligned}
& \frac{d^{2 x}}{d \theta^{2}}+2 n \frac{d x}{d \theta}+x=-\frac{a(\theta)}{\omega_{1}^{\prime} z_{0}} \quad-1<x<1 \\
& \frac{d^{2} x}{d \theta^{3}}+2 n \frac{d x}{d \theta}+(1-r)+r x=-\frac{a(\theta)}{\omega^{2} z_{0}} \quad x>1 \\
& \frac{d^{2} x}{d \theta^{2}}+2 n \frac{d x}{d 0}-(1-r)+r x=-\frac{a(\theta)}{\omega_{1}^{2} x_{0}} \quad x<-1
\end{aligned}
$$

For an earthquake of unfform spectral density equal to So with a Gaussian statistical distribution of the acceleration, and for:

$$
\begin{aligned}
& U=d x / d \theta \text { velocity, } \\
& F r=\text { restoring function of the unit of mass, } \\
& D_{0}=\text { value which we } w 1 l l \text { determine, } \\
& W=\text { transition function of the probability, }
\end{aligned}
$$

the Fokker-Planck equation has the form:

$$
\frac{\partial w}{\partial \theta}=-u \frac{\partial w}{\partial x}+(-F r) \frac{\partial w}{\partial u}+2 n w+D_{0} \frac{\partial x^{2}}{\partial u^{2}}
$$

and we should integrate in the three preceding domains with the condition $w_{\theta=0}(x, \theta)=\delta(x)$, where $\delta(x)$ is a Dirac function.

$w(x, \theta)_{\theta=0}$ is continuous for $x= \pm 1$.

The value of $D_{O}^{\prime}$ is related to the value of the spectral density So of the earthquake by:

$$
\therefore \quad \therefore \quad \overline{a^{\mathbf{a}}}=\int_{0}^{\infty} \mathbf{S}(\omega) d f_{t}
$$

I.e.:

i. .

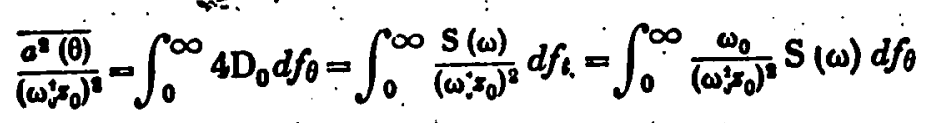

and therefore:

$$
D_{0}=\frac{S_{0}}{4 \omega_{0}^{3} x_{j}^{3}}
$$

We will not indicate-the ${ }^{x}$ sequence of calculations to integrate the Fokker-Planck equation, but will only give the results.

Wc let:

$$
\begin{aligned}
\Psi & =\frac{1}{2} \frac{D_{0}}{\bar{n}_{\text {eq }}} \\
Z_{0} & =\frac{G_{g}}{\omega_{0}^{2}}
\end{aligned}
$$

We give the tables of results in the case of the elasticplastic oscillator $(\beta=0)$. 


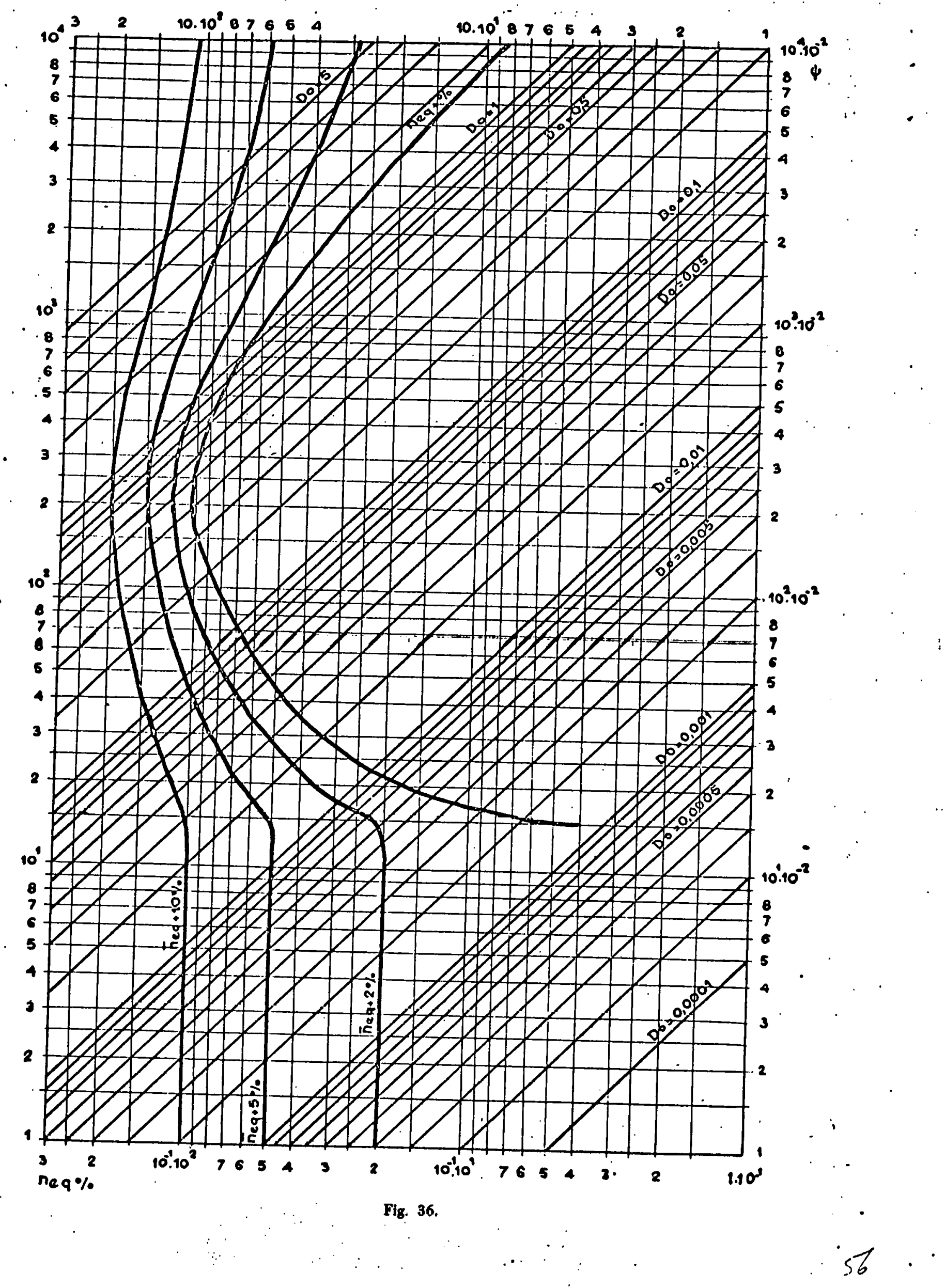




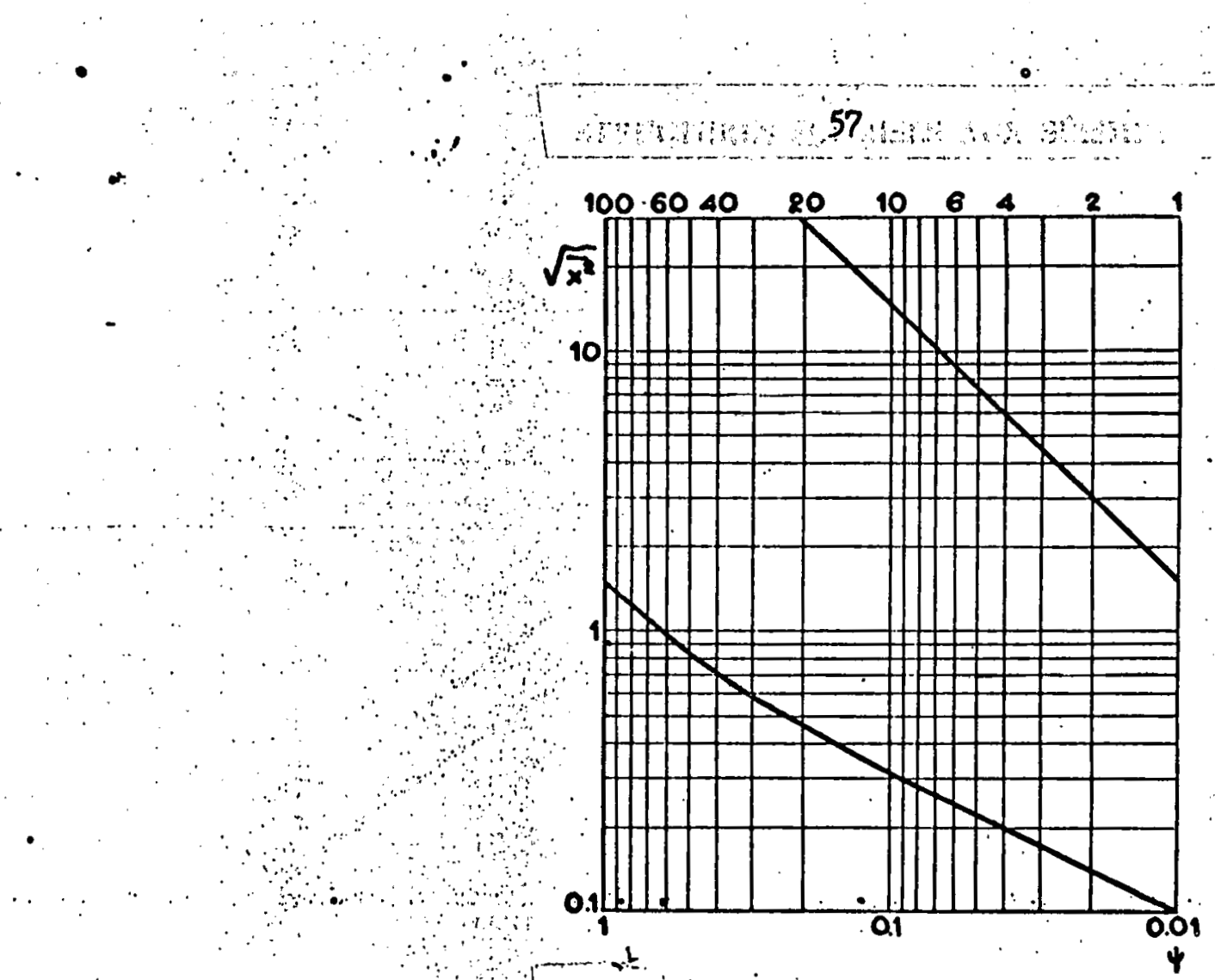

Fig. 37 .

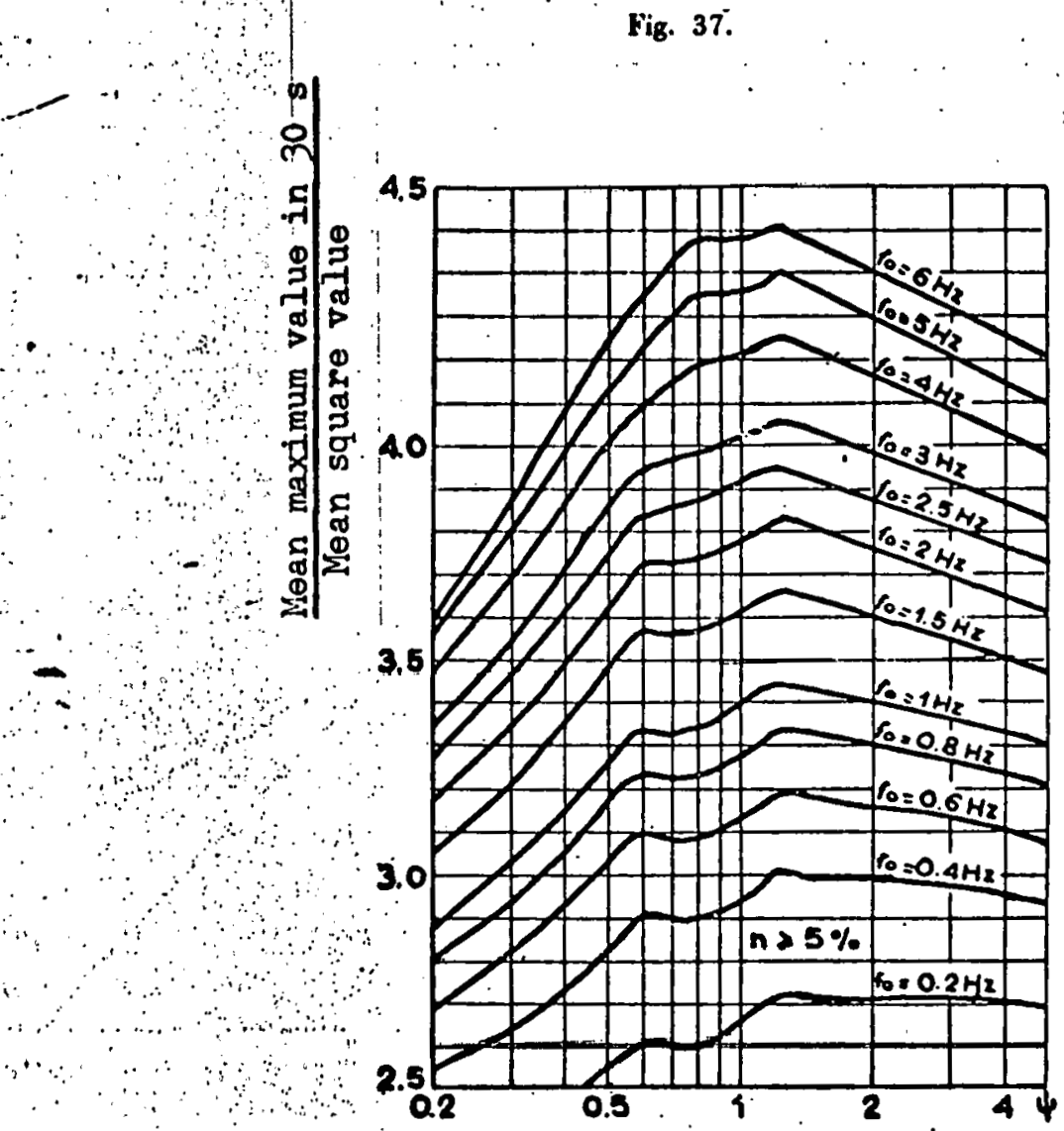

Fig. 38. 
FIg. 36 shows the relations between the parameters $D_{0}, \psi$ and $\overline{\mathrm{n}}_{\mathrm{eq}} \cdot$

F1g. 37 gives the mean square value $\sqrt{\hat{x}^{2}}$ as a function of $\psi$.

Fig. 38 shows the relation between the maximum mean value in $30 \mathrm{sec}$. and the mean square value as a function of $\psi$ and $f_{0}$.

Fig. 39 is the maximum mean displacement as a function of $\mathrm{G}$ for $\mathrm{n}=5 \%$ as a function of the period of the structure.

It is interesting to compare the results obtained for the elastic oscillator and those for the elastic-plastic oscillator with those reported by Bycroft (FIg. 40).

We see that the displacements in the case where the behavior is elastic and elastic-plastic are essentially the same.

This finding is of great importance, because it permits us to calculate the displacements of a structure in the case when its regime is elastic-plastic by assuming it to be infinitely elastic; but in order to calculate the stresses in the materials, we must take the elast1c-plastic state into account on the basis of the calculated deformations.

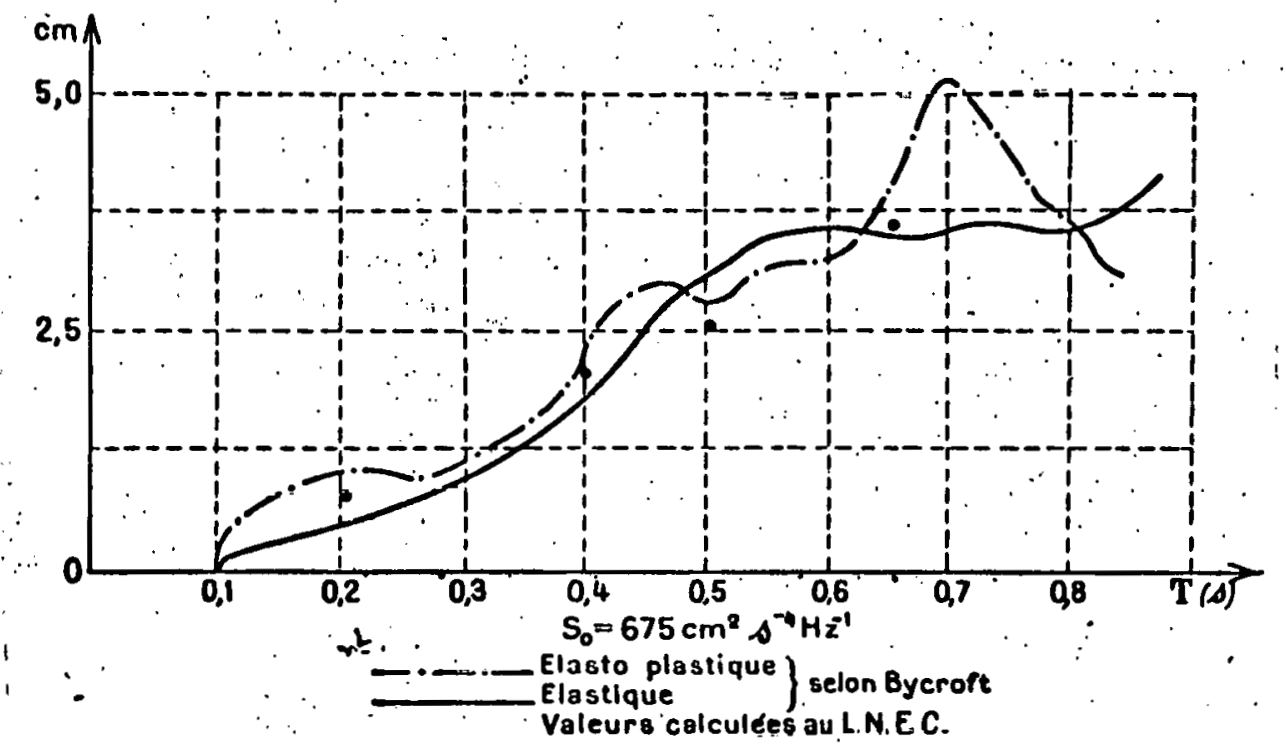

Elastic-plastic)

Fig. 40 Elastic acc. to Bycroft Values calculated at L.N.E.C. 


\section{Conclusion}

The methods of analytical studies which we have proposed permit us to obtain useful information on the behavior of structures and as a result of the powerful modern computers, these methods can lead to the solution of complicated problems.

Studies on a structural model have shown us the importance of the random characteristics of earthquakes. This subject therefore should be studied particularly so as to result in sultable representations of this phenomenon.

A statistical determination of rigldity matrixes based on model tests can be of great help to furnish future analytical solutions of these vibration problems (we can also determine these rigidity matrixes from flexibility matrixes, which are their inverse).

Dynamic tests with models in the elastic range can give complete information on the behavior of the structure; the determination of spectra (or transfer functions) is particularly recommended.

To evaluate the safety factor with respect to failure, it is necessary to examine the dynamic behavior in the non-linear domain. In the case of fragile structures, it may become necessary to study the behavior after cracks have developed.

With the use of simple rules, it is possible to combine economy and safety in structures of a conventional type, such as residential buildings.

In conclusion, we state that all structures are subject to dailluge caused by earthquakes because their natural frequencies are in the range of $0-5 \mathrm{~Hz}$ which is the effective range of selsmic shocks. 


\section{B1bllography}

A. Beles and M. Ifrim: Elements of Engineering Seismology. Editura Technicâ, Bucharest, 1962.

J. Ferry Borges: The Dimensioning of Structures. Publication No. 54, L.N.E.C., Lisbon, 1954.

J. Ferry Borges: Portuguese Studies on Earthquake-resistant Structures.

J. Ferry Borges: Seismic Design Criteria for Reinforced Concrete Buildings. L.N.E.C., June 1964.

J. Ferry Borges: Dynamic structural Studies on Models. I.N.E.C. Reports, July 1964.

J. Ferry Borges: How to Design Stmuctures to Resist Earthquakes? Report of L.N.E.C., September 1964 .

J. F. Borges and J. Pereira: Selsmic Studies on Concrete Dam Models. Paper No. 22, Presented to the Symposium on Concrete Dam Models, L.N.E.C. 1963.

J. Jervis Pereira: Study of the Dynamic Behavior of an ElasticPlastic Oscillator Activated by a Transient Stress. L.N.E.C., February 1964.

A. Pinto Ravara: Harmonic Analysis of Seismic Stresses. L.N.E.C., September 1953.

A. Pinto Ravara: Study of the Iinear Oscillator Stress by Seismic Effects. L.N.E.C., July 1963.

A. Pinto Ravara: Calculation of Seismic Forces in Lattice Structures by the Method of Modal Analysis. L.N.E.C., June 1963.

A. Pinto Ravara: Calculation of Selsmic Forces Generated in Vaulted Dams (Method of Modal Analysis). L.N.E.C., January 1964.

L.N.E.C.: Meeting on Earthquake-Resistant Construction, 1963. 